\title{
Recovery and Purification of (Bio)Pharmaceuticals Using (Nano)Materials
}

\author{
Ana P. M. Tavares, Márcia C. Neves, Tito Trindade and Mara G. Freire* \\ CICECO - Aveiro Institute of Materials, Department of Chemistry, University of Aveiro, 3810-193 \\ Aveiro, Portugal
}

\begin{abstract}
Biopharmaceuticals main classes comprise recombinant proteins, antibodies, and nucleic-acid-derived products, while synthetic pharmaceuticals include a wide variety of organic compounds. The purification of (bio)pharmaceuticals, as part of downstream processing, is mainly carried out by chromatographic processes, which are responsible for the therapeutics high cost. Therefore, there is a crucial need on the development of novel and more efficient separation/purification processes or on the improvement of the current chromatographic-based ones, aiming at producing pharmaceuticals of high quality and at a lower cost. Amongst alternative techniques, it has been demonstrated that inorganic or organic (nano)particles, used in solid-phase extraction approaches, may be promising for the purification of pharmaceuticals. This chapter provides an overview on solid-liquid separation/purification processes used to obtain high purity and high quality pharmaceuticals. The main purification processes are described and summarized. The areas where there has been a sustainable progress, combined with improved therapeutic characteristics, are highlighted. Materials based on silica (nano)particles, carbon-based (nano)particles (carbon nanotubes, graphene and activated carbon) and magnetic (nano)particles are overviewed. Based on the reported results, nanotechnology may play a key role in future pharmaceutical developments and manufacturing, where the design of suitable functionalized (nano)particles is a crucial factor to enhance the selectivity and to obtain high purification and recovery yields of (bio)pharmaceuticals.
\end{abstract}

Keywords: (Bio)pharmaceuticals, purification techniques, downstream processing, nanotechnology, silica (nano)particles, carbon-based (nano)particles, magnetic (nano)particles, pharmaceuticals manufacturing, solid-phase extraction, solid-liquid extraction.

\section{INTRODUCTION}

Pharmaceutical industries are indispensable for all public and private health care systems, and are responsible for the development, production and marketing of pharma products. Increasing market competition has prompted this sector to the search of new manufacturing processes, for which the pharmaceutical industry and academia have contributed to new production/recovery technologies for drugs [1].

*Corresponding author Mara G. Freire: CICECO - Aveiro Institute of Materials, Department of Chemistry, University of Aveiro, 3810-193 Aveiro, Portugal; E-mail: maragfreire@ua.pt 
The main pharmaceutical companies, known as Big Pharma, consist however on a small number of big multinational industries, such as Roche, Novartis, AstraZeneca, GlaxoSmithKline (GSK), Eli Lilly, Sanofi, Johnson \& Johnson, Merck, and Pfizer [1, 2].

Advances in the discovery of novel pharmaceuticals, with improved therapeutic efficacy and reduced side effects, contributed for the fast development of pharmaceutical industries [3]. Significant progresses in pharmaceuticals have been achieved by the optimization of both the upstream (production) and downstream (purification and recovery of the target product from complex media) processing, which include the search on new technologies and adaptation of the existing unit operations to increase efficiency, without the increase of the final product cost [4, 5]. In pharmaceutical industries, the lack of efficient downstream processes can seriously affect the success of a new product and even results in its failure. Thus, the search on alternative, more efficient and less costly downstream processing technologies is of crucial importance for the manufacturing of pharmaceuticals. In the past years, more than 60 scientific manuscripts addressing 'pharmaceuticals' and 'downstream processing' were published. Fig. 1 underlines the scientific publications trend in this field since 2000.
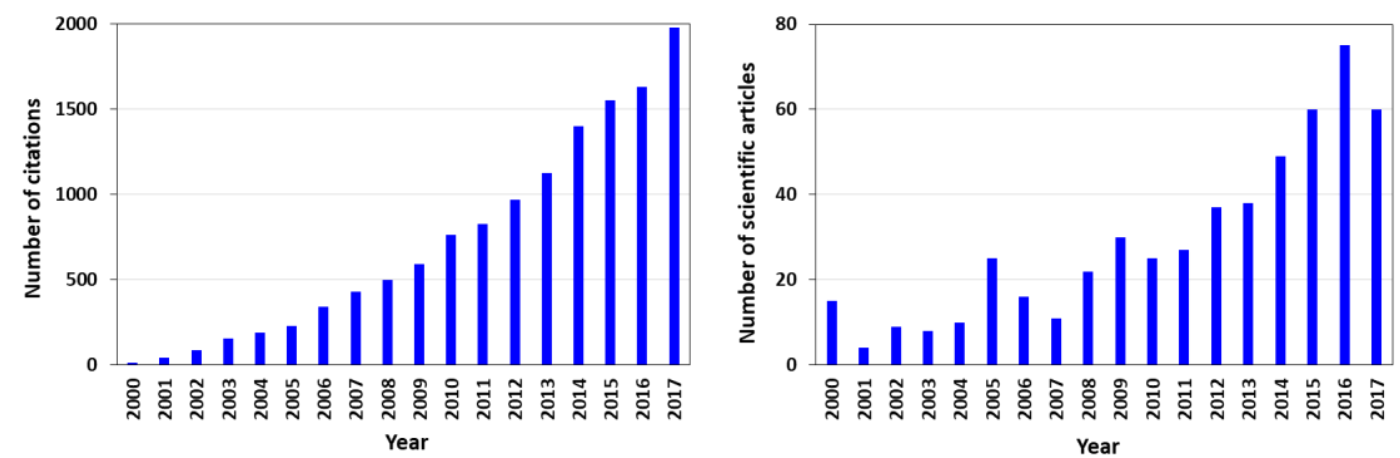

Figure 1: Number of scientific articles and total citations referring to "pharmaceuticals and downstream processing", from 2000 to 2017 (search on the ISI Web of Knowledge, May 2018).

In this book chapter, an overview on pharmaceutical industry processes, on existing methods for process optimization and integration, and on innovative approaches, is provided. In particular, downstream processing technologies based on the use of (nano)particles for the purification of pharmaceuticals are presented and discussed in detail.

\section{SEPARATION AND PURIFICATION OF PHARMACEUTICALS}

Classical pharmaceuticals are low molecular weight organic compounds, known as medicines or drugs, used as main active compounds in today's therapeutic 
approaches. These compounds comprise more than $90 \%$ of the currently available drugs [6]. On the other hand, biological compounds with therapeutic activity, known as biopharmaceuticals, biotechnology medicines or biologics, are pharmaceuticals derived from living organisms, such as bacteria, yeast, animal or human cells, viruses, and transgenic animals or plants [7]. The designation of 'biopharmaceutical' was first adopted in the 80's [8], and then used to define a class of therapeutic proteins produced by genetic engineering or by hybridoma technology [8]. Currently, biopharmaceuticals represent one of the most promising frontiers in medicine [6]. Biopharmaceutical products include vaccines, cell or gene therapies, plant extracts, recombinant therapeutic proteins, cytokines and tissue growth factors, blood components or derivatives, among others [9, 10]. The first manufactured biopharmaceutical, approved in 1982 by the US Food and Drug Administration (FDA), was the recombinant DNA human insulin produced by Escherichia coli $[11,12]$. Currently, up to 650 protein-based biopharmaceuticals have been approved worldwide [13]. Biopharmaceuticals can be applied not only in the treatment of diverse diseases, but also in clinical diagnosis and prevention strategies $[8,14]$. It is however required that such products are safe, effective, of good quality, and prescribed and used rationally.

Biopharmaceuticals are distinct from chemical drugs. Synthetic drugs are small organic molecules, typically obtained through chemical synthesis. On the other hand, almost all biologic-derived pharmaceuticals are composed of more structural complex molecules with high molecular weight. As a result, the full characterization of biopharmaceuticals is more difficult to achieve [15, 16]. Fig. 2 illustrates the chemical structure of a traditional small synthetic molecule drug, namely ibuprofen, and of a complex biopharmaceutical structure, namely an antibody (IgG). 


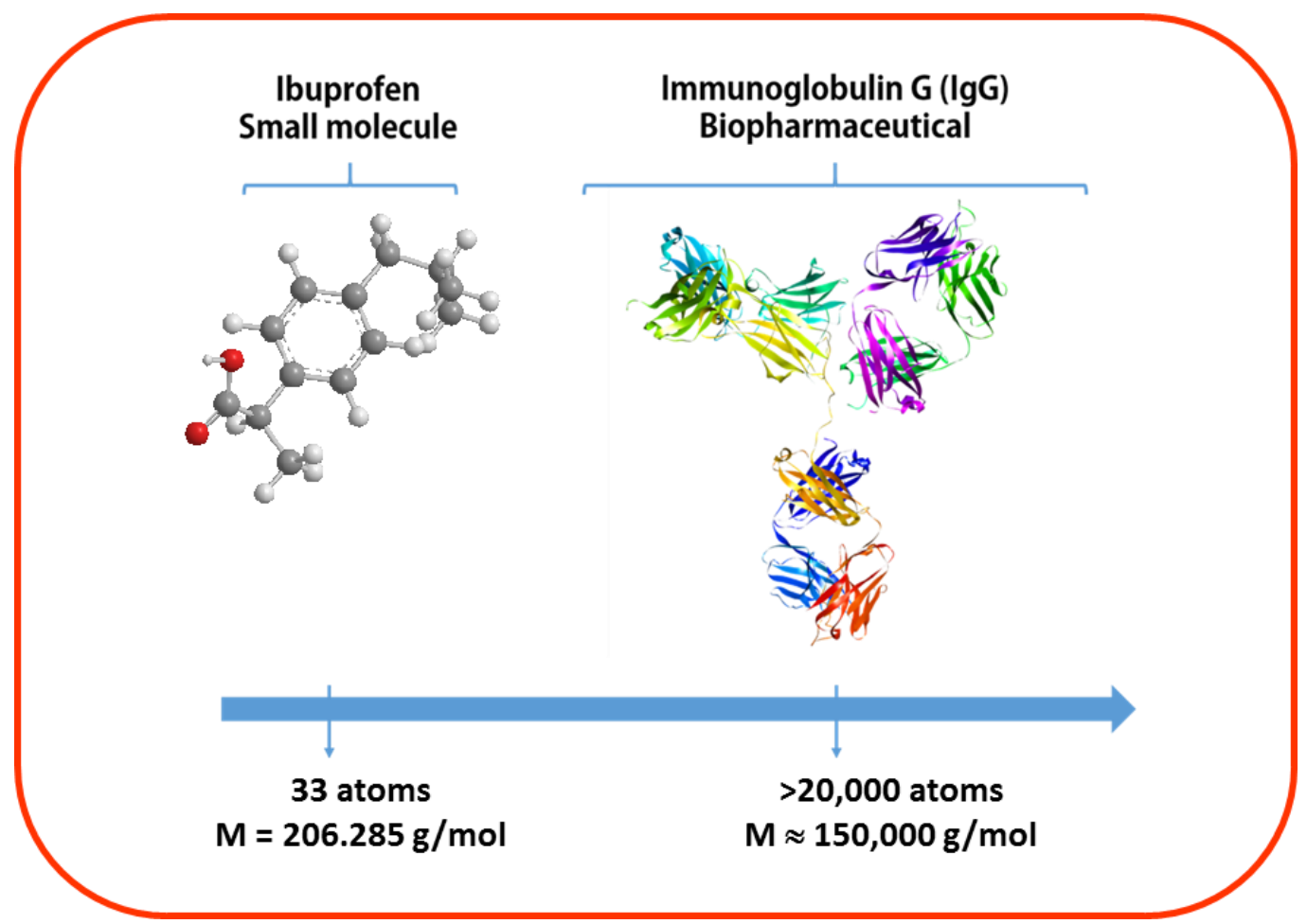

Figure 2: Comparison between a synthetic organic molecule (ibuprofen) and a biopharmaceutical (IgG antibody). (IgG crystal structure taken from the Protein Data Base: 1h2h).

Additional differences between synthetic pharmaceuticals and biopharmaceuticals, summarized in Table 1, include product and active agent sources, composition, manufacturing methods and equipment, purification strategies, formulation, handling, dosing, immunogenicity, regulation and marketing [17, 18]. Biopharmaceuticals are more difficult to be approved than smaller synthetic drugs, mainly due to their production processes and environment in which they are produced. Compared to synthetic pharmaceuticals, typically requiring the use of harsh conditions for their synthesis, high temperatures and pressures and the use of organic solvents, the production of biopharmaceuticals is carried out at milder temperature, $\mathrm{pH}$ and pressure conditions [7]. However, the former are present in a more complex matrix and require multi-step processes for their purification [18]. More details on the manufacturing processes are given in "pharmaceuticals manufacturing" section presented below. 
Table 1: Main differences between synthetic pharmaceuticals and biopharmaceuticals [9].

\begin{tabular}{|l|l|l|}
\hline Properties & Pharmaceuticals & Biopharmaceuticals \\
\hline Source & Chemicals & $\begin{array}{l}\text { Living systems: microorganism, or plant } \\
\text { or animal cells }\end{array}$ \\
\hline $\begin{array}{l}\text { Structure and } \\
\text { characteristics }\end{array}$ & $\begin{array}{l}\text { Small molecules with defined } \\
\text { chemical structure, highly stable }\end{array}$ & $\begin{array}{l}\text { Large and complex molecules or } \\
\text { mixture of molecules }\end{array}$ \\
\hline Composition & Easy to characterize & Hard to characterize \\
\hline Manufacturing method & Chemical synthesis & Biological process \\
\hline Intellectual property (IP) & Full protected & $\begin{array}{l}\text { IP protection is more intricate since it } \\
\text { requires both the target drug } \\
\text { characterization and evaluation of the } \\
\text { process reliability and safety in living } \\
\text { systems }\end{array}$ \\
\hline Handling & Relatively stable & $\begin{array}{l}\text { Sensitive to process, storage and } \\
\text { handling conditions }\end{array}$ \\
\hline $\begin{array}{l}\text { Regulation and } \\
\text { marketing }\end{array}$ & $\begin{array}{l}\text { Relatively easy, must be } \\
\text { identical to reference product } \\
\text { regulate, must be highly similar to } \\
\text { reference product }\end{array}$ \\
\hline Commercial price & Relatively low cost & Relatively high cost \\
\hline
\end{tabular}

\section{Biosimilars and generic drugs}

Compared to biopharmaceuticals, generic synthetic drugs are easier to prepare due to their smaller size and lower structural complexity. Thus, an exact copy of the original product, i.e. a generic drug (off-patent), can be directly manufactured and reproduced using traditional processes [19]. Generic drugs must only present identical chemical composition to the original product and bioavailability studies to validate whether the pharmacokinetic properties of the generic and reference products are similar [20].

Biosimilars (term adopted by the European Medicines Agency (EMA)) or followon biopharmaceuticals (term adopted by the FDA) [18, 19, 21-23] are a viable therapeutic option. A biosimilar is any medicinal product from a biological source with an established biosimilarity with the original biologic product [24]. Biosimilars possess the same active substances of an already authorized biopharmaceutical; however, small differences can be found due to their complexity and production methodologies. The similarity between the biosimilar product and the corresponding biopharmaceutical, in terms of safety, purity, risks and efficacy, must be well established and must lead to the same clinical results as the original product [24, 25]; however, biosimilar products should provide cost savings.

The first generation of biopharmaceuticals was commercialized in the early 80's, and their patents protection has expired or are reaching their expiration date, allowing thus similar biopharmaceuticals to enter into the market [18]. Many 
biosimilars, including the monoclonal antibodies CT-P13 (Remsima $® /$ Inflectra $\AA$, an infliximab biosimilar) and SB2 (Flixabi ${ }^{\circledR}$, an infliximab biosimilar), the protein SB4 (Benepali®, an etanercept biosimilar), among others, are now commercially available for the treatment of diverse diseases. Currently, 13 distinct biosimilar drugs have received marketing approval in the European Union and this number is still increasing [26]. Accordingly, the EMA has developed regulatory guidelines on biosimilar medicinal products to help medicine developers in the preparation of marketing authorisation.

In summary, unlike for generic synthetic drugs, the production of biosimilars is more complex because it is not possible to mimic the original biopharmaceutical due to the complexity of the production processes and molecular heterogeneity (complex mixture of molecular entities, their structural variants, and impurities). Minor variations in the process, such as temperature, $\mathrm{pH}$, formulation, downstream process or storage can also lead to changes in the final product [27]. This variability is not detected in the production of generic synthetic drugs since their production is more consistent, reproducible and robust [19].

\section{Synthetic drugs}

Traditional drugs have been manufactured for decades through chemical synthesis based on unique batch-type operational models [5, 28]. The final active pharmaceutical ingredient (API) is then incorporated in liquids, tablets, capsules, creams or aerosols formulations [29]. Synthetic drugs are manufactured in batch reactors (several stages of chemical reactions), followed by a purification process and further packaging and storage of the final product [28, 30]. Fig. 3 depicts a scheme of the main steps occurring in the manufacturing of synthetic pharmaceuticals. Other steps including different unit operations, such as granulation, mixing, filtration, heat exchangers, distillation, crystallization, printing, coating and filling, can be used (or not) depending on the active pharmaceutical ingredient (API). All these stages generate solid (mainly sludge containing toxic organic compounds), liquid (composition depends on the type of product) and gas (volatile organic compounds) wastes which are treated in distinct steps [31]. 


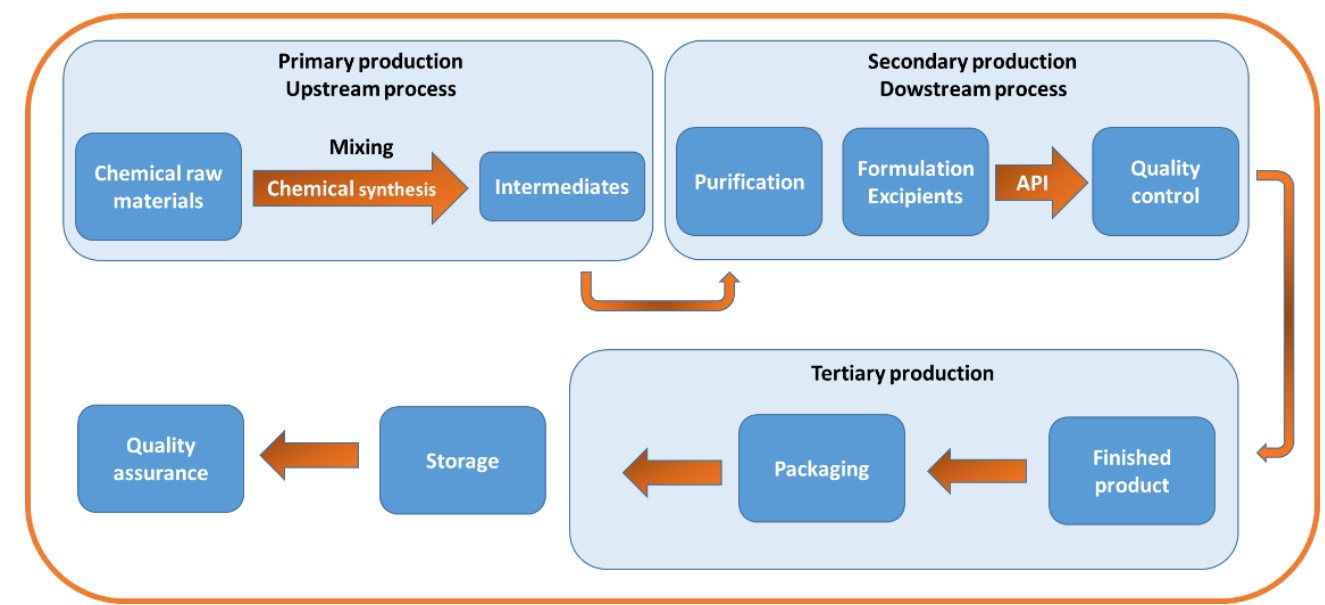

Figure 3: Scheme representing synthetic drugs manufacturing processes.

Recently, pharmaceutical industries and FDA agreed in changing the pharmaceuticals manufacturing from the traditional batch process to a continuous process technology $[32,33]$. The objective of pharmaceutical industries is now to convert selected unit operations and processes from batch to continuous mode [34]. The potential advantages in continuous manufacturing comprise a reduction on the process cost, increased productivity, better control of the product quality, and improved flexibility and robustness in production [32, 35]. A continuous pharmaceutical process can be divided into three main parts: i) individual connected (continuous) unit operations; ii) real-time data for process monitoring and control; and iii) process variability in terms of quality of the final products [35]. However, before commercialization of a target pharmaceutical, competent authorities must approve regulatory and quality controls for the product $[35,36]$. In 2016, FDA approved, for the first time, the update of a manufacturing method from batch manufacturing to a continuous manufacturing process for the pharmaceutical sold under the brand name Prezista ${ }^{\circledR}$ (API: darunavir) at Janssen's Gurabo, Puerto Rico plant [37].

More recently, manufacture of 3D-printed drug products has gained a great interest within the pharmaceutical industry [38], and intensive research has been developed in this field [39]. The first 3D-printed drug based on powder bed-liquid, Spritam ${ }^{\circledR}$ (levetiracetam), was approved by FDA in 2015 for the treatment of epilepsy [38, 40]. The special advantages of 3D printed drugs include the possibility to create: i) complex products - and to modify how drugs interact; ii) personalized products to reduce side effects; and iii) products made for immediate consumption. Compared to traditional pharmaceutical manufacturing, 3D printing is exclusive in terms of product complexity, flexibility and throughput [41]. 


\section{Biopharmaceuticals}

Biopharmaceuticals are a growing sector of the pharmaceutical industry [8]. As already mentioned, biologic manufacturing or biomanufacturing is a multifaceted and complex process, comprising various steps, involving cell culture systems based on yeast or bacteria living organisms, biological complex matrices, animal and mammalian cell cultures [42]. The main differences between synthetic drugs and biopharmaceuticals manufacturing convey on the use of living organisms, impact of the process on the product, and complexity of the biomolecules produced [7]. Usually, biopharmaceuticals are produced by recombinant DNA technology via genetically engineered living cells. For this purpose, a DNA sequence is introduced into the host cell of the living organism, which produces the target biomolecule. However, in the past few years, an increase in the biopharmaceuticals manufacture from mammalian cell cultures over non-mammalian systems has been observed [ 8 , 43]. For instance, insulin is a product produced by microbial systems (by recombinant DNA technology), whilst antibodies are produced by mammalian systems (mainly Chinese hamster ovary (CHO) cell-based systems) [8]. Currently, the leaders of the biopharmaceutical industry are recombinant proteins and monoclonal antibodies, with ca. 200 biopharmaceuticals approved and under commercialization [6, 44].

The production, purification and recovery of biopharmaceuticals require a multistep approach, in which an accurate quality control and extensive monitoring must be employed. A minor change in the process or materials, including equipment or facilities, can result in significant variations of the final product profile (molecular conformation shift) and, as a consequence, more clinical tests will be required to validate the product's safety, efficacy and purity [7]. It is the responsibility of the manufacturer to validate, with the regulatory authorities, the impact (if any) of the changes in the manufacturing process on the biopharmaceutical product [7]. A traditional cell culture biopharmaceutical process can be divided into four stages (Fig. 4): i) media preparation/cell growth; ii) fermentation (upstream); iii) purification (downstream); and iv) formulation/delivery. These can be processed by three main operations: batch, fed-batch, and perfusion. The entire process can be divided into nine main stages: i) cell line system; ii) cell culture; iii) harvest; iv) purification; v) formulation; vi) filling; vii) finishing; viii) packaging; and ix) storage $[25,45]$. Various unit operations such as chromatography, centrifugation, ultrafiltration, flotation and filtration are used during the overall manufacturing process.

The upstream process includes operations first related to cell growth in a large bioreactor system (fermenter), where the targeted biomolecule is expressed. The 
fermentation is developed under controlled conditions, such as $\mathrm{pH}$ and temperature, and must be protected from the risk of contamination by other microorganisms. During the downstream processing, commonly denoted as purification process, the biopharmaceutical is purified and isolated to obtain the final product. This is carried out through several purification steps, including filtration, chromatography, and tangential flow filtration. In the finishing operation, the final product is placed in its delivery container [46]. The entire process is strictly regulated by FDA, EMA and/or other international regulatory agencies to guarantee the safety and efficacy of these bio-based drugs [25].

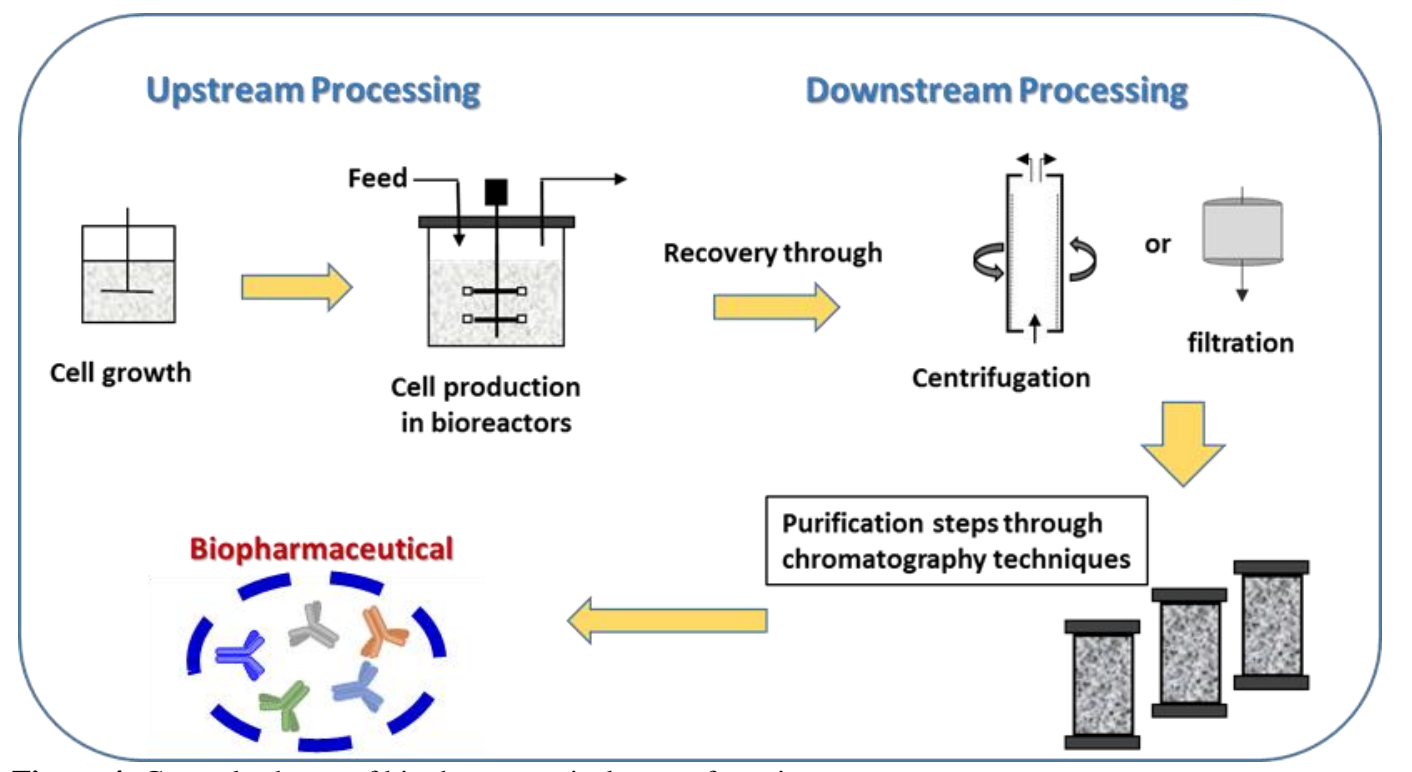

Figure 4: General scheme of biopharmaceuticals manufacturing process.

Biopharmaceuticals are heavily regulated by authorities, which require an intensive quality control in order to comply with all regulations, as well as the efficacy and safety use guarantees. Regular quality control samples and final release specifications are conducted before approving a given batch [46]. These specifications are controlled both by quantitative and/or qualitative approaches. FDA and the International Conference on Harmonisation of Technical Requirements for Registration of Pharmaceuticals for Human Use (ICH) have approved the following quality elements for biopharmaceuticals: quality system, materials system, facilities and equipment system, production system, laboratory control system, packaging and labelling system [25]. 


\section{APPLICATIONS OF INORGANIC (NANO)MATERIALS IN THE PREPARATION OF PHARMACEUTICALS}

According to the report "Separation Systems for Commercial Biotechnology", the global market for commercial biotechnology separation systems reached nearly $\$ 16$ billion in 2012, and was around $\$ 17$ billion in 2013 [47]. This market is expected to grow at a compound annual growth rate (CAGR) of $10.1 \%$, reaching a value of $\$ 27.8$ billion by 2018 [47]. Despite their high cost, difficulty in scaling-up and low throughput, currently, the preferred separation techniques in downstream processing are dominated by chromatography approaches and membrane filtration, which together account for $36 \%$ of the global biotechnology separations market [47]. The most used approaches for (bio)molecules separation are based on liquid chromatography (ion exchange, affinity, thin layer, flash, high performance), membrane filtration, centrifugation and electrophoresis. Nevertheless, less traditional separation methodologies, such as microarray, biochip and lab-on-achip, flow cytometry, use of solid supports and magnetic separation, have been also proposed [47].

Liquid chromatography is one of the most important stages in purification processes [48]. In order to develop an efficient purification method based on chromatography, it is mandatory to know the composition of the mixture, the molecular properties of the solutes and how they interact with the stationary phase. Separation processes based on size exclusion chromatography (SEC) take into account the differences in molecular sizes; hydrophobic interaction chromatography (HIC) and reversedphase chromatography (RPC) are based on surface hydrophobicity differences; ionexchange chromatography (IEC) takes advantage of the charge differences to separate the compounds; and mixed-mode chromatography (MMC) combines the various strategies [48].

\section{Silica (nano)particles}

Silica gel is one of the most widely used adsorbent materials for the purification of a wide range of (bio)compounds, a result of its low cost, easy handling, high surface area, and high mechanical, thermal and chemical stabilities [49, 50]. However, the purification or removal of organic compounds at ultra-trace levels using silica gel is rarely achieved, and attempts to its surface modification are usually carried out to increase selectivity and adsorption efficiency [49]. Solid matrices functionalized with phenyl, cyano, trimethylsilane, triazole, amines, cyclodextrine and dihydropropane groups were already applied in the purification of diverse drug products [49-51]. 
The use of amorphous silica (nano)particles for the purification of APIs using solidphase extraction (SPE) offers many advantages for the pharmaceutical industry. Benefits of this approach include the speed, reproducibility and efficiency [52]. This methodology is however mainly used for the purification of biologics. Up to date, and according to the literature available, no synthetic drugs envisaged for therapeutic use were extracted or purified through silica (nano)particles in SPE. Thus, this section presents a general description of this extraction technique for biologics and provides several examples of its application in biopharmaceuticals purification.

In affinity chromatography, the separation of the target product is based on the reversible interactions occurring between the product and a specific ligand. The target product is captured, whereas all contaminants are ideally excluded in a single step [53]. Affinity chromatography is the most selective type of chromatography used in biotechnology due to its high selectivity, robustness and straightforward implementation for new products. Occasionally, to increase the amount of the biopharmaceutical aimed to be purified, the dimensions of the chromatographic column are increased. However, there are drawbacks associated to the use of large columns, such as the high load of adsorbent material employed, which deforms the stationary phase and restricts the flow. An alternative to these conditions is to perform the purification in several cycles, thus decreasing the amount of the stationary phase. An additional possibility is to perform the SPE process in solution instead of packed-bed chromatography. Other techniques have also been studied for biopharmaceuticals purification, such as liquid-liquid extraction using aqueous biphasic systems [14, 54], magnetic separation [55-59] and affinity membranes [60, 61]. Separation using silica coated magnetic materials and affinity membranes are non-chromatographic techniques involving affinity ligands at their surfaces. Affinity ligands based on triazine scaffold [59, 62], boronic acids [63] and ligands with a thiol functional group $[56,57]$ have been described in the literature for biopharmaceuticals purification.

The silica surface can be chemically functionalized with silicon alkoxides, such as methyltriethoxysilane (-Me), 3-mercaptopropyltriethoxysilane (-SH), 3glycidoxypropyltriethoxysilane (-Gly), and 3-aminopropyltriethoxyilane (-NH2) (Fig. 5) [64]. These functionalized surfaces can be further modified with antibodies and proteins [64-67]. Hikosaka et al. [64] developed an Immunoglobulin G (IgG) purification affinity material based on this strategy, in which four mesoporous silica materials with two morphologies (spherical (MCM-41s and MCM-48s) and polyhedral (MCM-41p and MCM-48p)) were used. After functionalization with different organosilanes, anti-IgG is adsorbed and the FITC-IgG binding efficiency was evaluated. Although these materials have shown capacity to adsorb anti-IgG, the highest binding efficiency for FITC-IgG was observed with MCM-41p, 
followed by MCM-41s. The mesoporous silica MCM-48 type showed approximately half of the value of binding efficiency obtained with the MCM-41 type. The porosity of these two types of mesoporous silica can explain such behavior; MCM-41s has a superficial cylindrical pore structure in one direction, while MCM-48s has a 3D pore system. Due to an inadequate orientation of the antiIgG Fab region in MCM-48 materials, the binding of FITC-IgG to anti-IgG introduced into the pores is more difficult. Regarding the functionalization, the MCM-41p material showed the highest binding efficiency. MCM-41p-Me and MCM-41p-SH are good anti-IgG adsorbents; yet, the adsorption efficiency decreases significantly for MCM-41p-Gly, and anti-IgG is poorly adsorbed by MCM-41p-NH 2 [64].

Another example on the combination of affinity ligands with pore size and structure of the adsorbent was published by Nakanishi et al. [66]. In this case, the surface of mesoporous silica particles characterized by distinct pore sizes, namely $2.3,2.7$, 12.4, 22.4, and $31.2 \mathrm{~nm}$, was functionalized with $\mathrm{g}$ glycidoxypropyltrimethoxysilane (-Gly), phenyltriethoxysilane (-Ph) and 3mercaptopropyltrimethoxysilane (-SH) and then loaded with Staphylococcal protein-A for the specific binding of IgG. The adsorption of IgG in the mesoporous silica-protein A composites was analyzed as a function of the pore size and surface properties. The adsorbent with the highest IgG binding efficiency was mesoporous silica with pores of approximately $2.7 \mathrm{~nm}$ and functionalized with Gly. This behavior was explained based on chemical (glycidoxy group and protein A linkages) and morphological (different pores' sizes) features. This material exhibited a high (complete) IgG adsorption capacity [66]. 


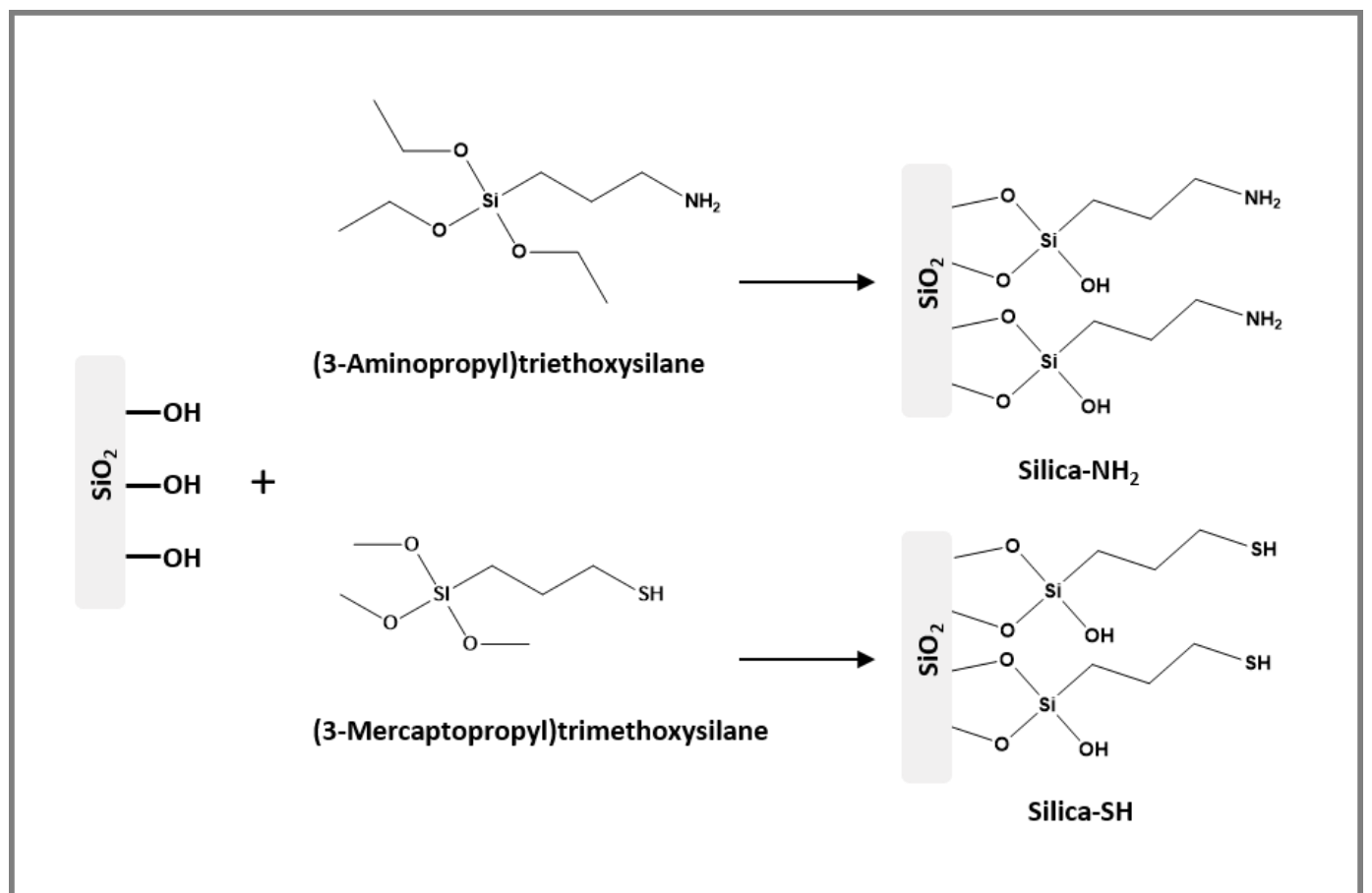

Figure 5: Examples of silica functionalization with different organosilanes (3-mercaptopropyltriethoxysilane (-SH) and 3-aminopropyltriethoxyilane (-NH2)).

Core-shell microspheres have been used as specific adsorbent materials for IgG. The advantages of this material were combined with the surface printing strategy [67]. The silica surface was activated by acid treatment and modified with 3methacryloyloxypropyl trimethoxysilane. By using N-methacryloyl-L-aspartic acid as complexing/functional monomer, the IgG molecules were printed on the surface of the core-shell material. The core-shell microspheres were then washed repeatedly with a $0.5 \mathrm{M} \mathrm{NaCl}$ solution to remove the template $\mathrm{IgG}$ molecules (Fig. 6) [67]. These core-shell materials were studied as IgG adsorbents from aqueous solutions to evaluate the best adsorption conditions and parameters, such as $\mathrm{pH}$, IgG concentration, ionic strength and temperature. For comparison, the adsorption of IgG on core-shell silica particles prepared without IgG as template was also evaluated. The best results were obtained at $\mathrm{pH} 6$ due to electrostatic interactions established between IgG (pI 6.2) and the core-shell silica particles with aspartic acid (pI 2.7) on the surface. The adsorption capacity decreases with increasing temperature indicating that the main interactions established between the core-shell adsorbent and the $\operatorname{IgG}$ molecules are electrostatic and hydrogen-bonding interactions. An increase in the $\mathrm{NaCl}$ concentration increases the $\mathrm{IgG}$ solution ionic strength, causing a lower adsorption due to the coordination of the deprotonated 
aspartic acid by the carboxyl group. The selectivity of the imprinted core-shell microspheres was also investigated using human serum albumin (HSA) and hemoglobin $(\mathrm{Hb})$ as competing proteins. These adsorbent materials showed a high ability to recognize the target molecule, in this case the $\operatorname{IgG}$ in a 4.31 ratio with respect to $\mathrm{HSA}$ and 2.68 ratio with respect to $\mathrm{Hb}$ [67].

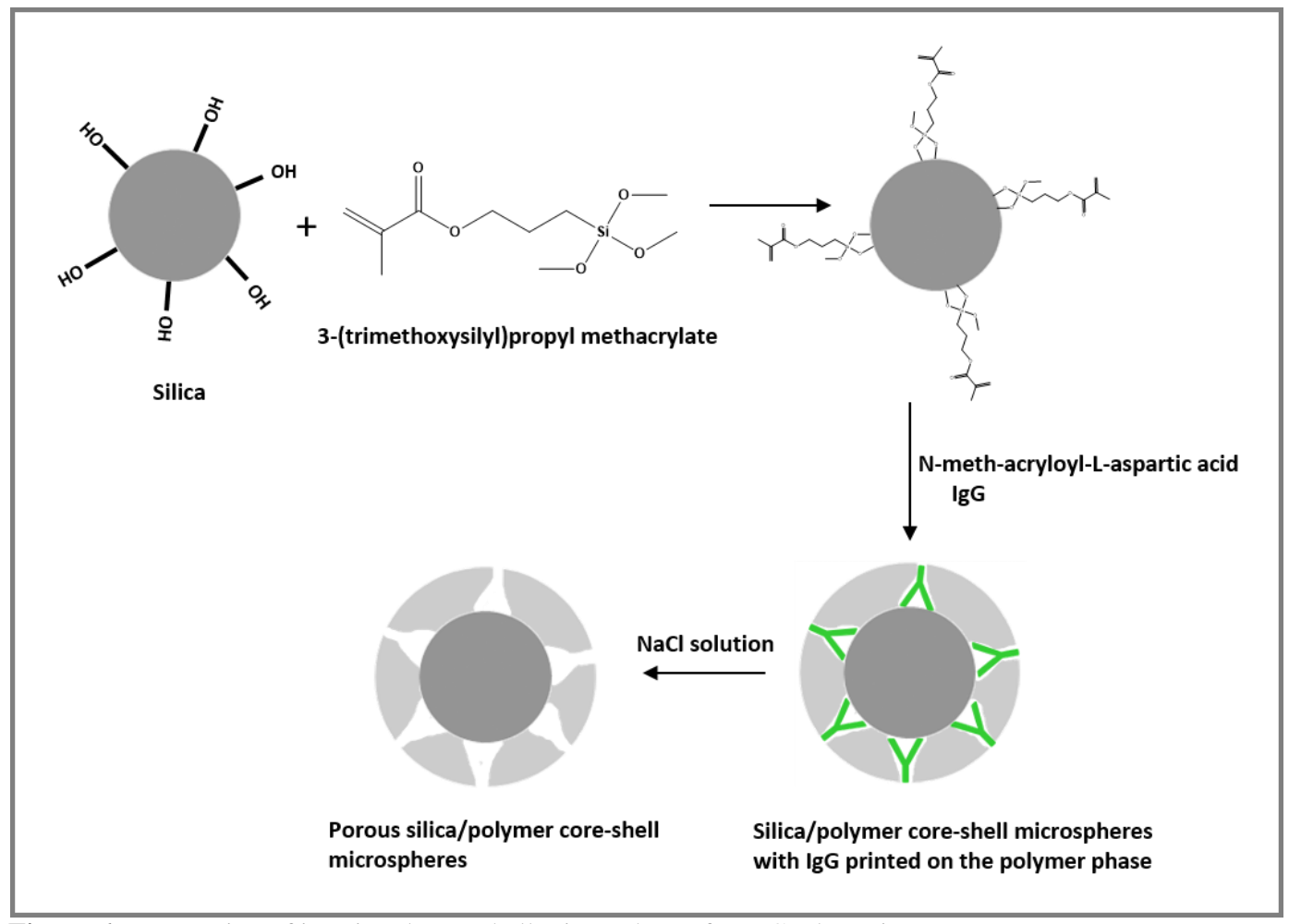

Figure 6: Preparation of imprinted core-shell microspheres for IgG adsorption.

Silica functionalized with 3-mercaptopropyltrimethoxysilane was studied for the purification of glutathione S-transferase (GST) from cell lysate of the liver of mouse [65]. The $\mathrm{SiO}_{2}-\mathrm{SH}$ microspheres were firstly modified with reduced glutathione (GSH) to generate $\mathrm{SiO}_{2}-\mathrm{GSH}$. Both $\mathrm{SiO}_{2}-\mathrm{SH}$ and $\mathrm{SiO}_{2}-\mathrm{GSH}$ were used for the affinity separation of GSH from a mixed protein solution. In this wok, SDS-PAGE was performed to qualitatively assess the validity of the protein separation procedure. Although both materials can adsorb GSH, the SiO2-GSH was the most promise material since it is able to specifically bind to the target protein [65].

Bufadienolides, an anticancer compound, was isolated from Bufo bufo gargarizans Cantor toad skin using porous silica particles with bonded $\beta$-cyclodextrine (CD) [68]. A high purity isolation of target compounds (from 81.84 to $99.99 \%$ ), namely the hellebrigenin stereoisomer, $\psi$-bufarenogin, gamabufotalin, bufarenogin, 
arenobufagin stereoisomer and arenobufagin, was easily and efficiently achieved because of the powerful separation ability of the used orthogonal isolation system. The main advantages of the proposed method comprise: i) high-purity isolation of active compounds from natural products and high efficiency; and ii) potential to isolate stereoisomers from natural products [68].

Currently, many methods for protein purification comprise a separation step based on specific interactions between immobilized ligands and affinity tags on the protein. One of the most popular labels is polyhistidine, which binds strongly to divalent metal ions present in proteins, such as $\mathrm{Ni}^{2+}$ and $\mathrm{Co}^{2+}$ ions. Thus, adsorbents with $\mathrm{Ni}^{2+}$ ions can be used to separate His-tagged proteins. This purification strategy was applied to the separation of His-tagged proteins from the Escherichia coli cell lysate mixture [69]. In order to obtain a high density of metal ions immobilized at the surfaces, materials with dual functionalization were prepared by combining the affinity separation to the high surface area provided by silica hollow nanoparticles [69]. Hollow silica functionalized with tiol groups (-SH) were initially synthesized, having a diameter of $45 \mathrm{~nm}$ and a shell thickness of $10 \mathrm{~nm}$. Then, conjugation with iminodiacetic acid (IDA) was applied to confer double chelating groups to the silica surface (-SH and $-\mathrm{COOH})$. The adsorbent hollow material was studied as His-tag proteins adsorbent materials after chelation with $\mathrm{Ni}^{2+}$. His-tag proteins were recovered from the silica functionalized material by washing with an imidazolium-based salt solution. The $\mathrm{Ni}^{2+}$ loaded silica material showed a high adsorption specificity and capacity for the target proteins, and can be reused [69].

Supported ionic liquids (SILs) materials have been used in the separation and purification of several natural products and biopharmaceuticals [70]. The immobilization of ILs onto support materials can be achieved by two routes: covalent bonding of IL fragments to the support (Fig. 7) or physisorption via van der Waals and dipole forces [71]. SILs already demonstrated to exhibit outstanding properties, namely a high surface area, high thermal stability, application in fixedbed or fluidized-bed technologies, and efficient catalyst immobilization [72]. Such properties ruled their exploration in several research fields, such as in catalysis, separation and extraction processes [72]. SPE with materials modified with ILs was employed for the purification of lactic acid from a fermentation broth [73]. Silica was functionalized with imidazole, 1-methylimidazole and 2-ethyl-4methylimidazole with chloride acting as the counterion. The material functionalized with imidazolium showed the best results, with a yield of adsorption of $91.9 \%$. The mechanism of adsorption of lactic acid to the SIL is based on the anion exchange of the chloride ion by the lactate ion. SIL recycling has been demonstrated, potentiating these materials in the development of economically viable industrial applications [73]. 


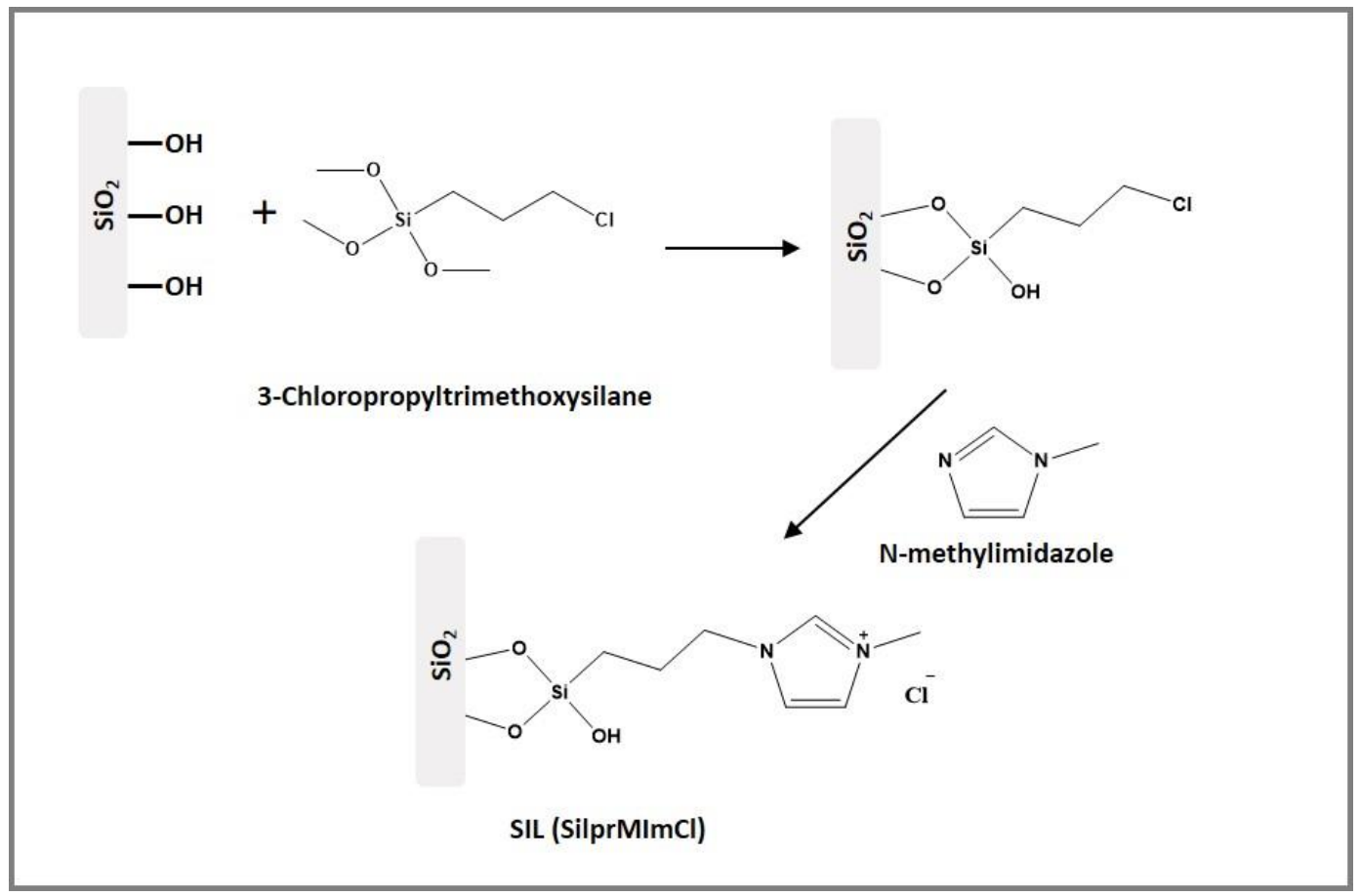

Figure 7: Example of ionic liquids immobilization for the preparation of SIL materials.

\section{Carbon-based (nano)materials}

During the last years a great progress has been achieved in the development of new carbon nanomaterials (CNMs) for chemical synthesis, drug delivery, and adsorption/desorption of (bio)molecules with improved performance [74]. These progresses are of high importance to produce highly pure (bio)pharmaceuticals. As it happens with other nanomaterials, it is of great relevance the exploration of unique and specific properties of CNMs, such as morphology, chemical reactivity and physical properties. Additionally, due to their nanosize, unconventional interactions between the material and living organisms can occur [75]. However, due to their poor solubility in water and potential cytotoxicity, their applications in vivo are still of concern in biomedical and pharmaceutical applications [76]. The most recent applications of carbon materials in pharmaceutical industry are detailed below and summarized in Table 2 .

Table 2: Recent applications of carbon materials for the purification of pharmaceuticals.

\begin{tabular}{|c|c|c|c|}
\hline Material & (Bio)pharmaceutical & Recovery & Reference \\
\hline SWCNTs* $^{*}$ & Carvedilol stereoisomers & $>97 \%$ & (Silva et al., 2012) [77] \\
\hline
\end{tabular}




\begin{tabular}{|c|c|c|c|}
\hline MWCNT & Clenbuterol & NA & (Yu et al., 2011) [78] \\
\hline $\begin{array}{c}\text { SWCNTs and } \\
\text { MWCNTs }\end{array}$ & Cephalosporins & $>80 \%$ & (Niu et al., 2007) [79] \\
\hline Magnetic CNTs & Fluoroquinolones & $>95 \%$ & (Xiao et al., 2013) [80] \\
\hline Magnetic MCNTs & Lysozyme & $97.8 \%$. & (Chen et al., 2015) [81] \\
\hline Graphene oxide & Lysozyme & $94 \%$ & (Ding et al., 2015) [82] \\
\hline Graphene oxide & Lysozyme & $90 \%$ & (Liu et al., 2013) [83] \\
\hline Graphene oxide & Lysozyme & NA & (Qu et al., 2012) [84] \\
\hline Graphene oxide & Haemoglobin & $80 \%$ & (Liu et al., 2011) [85] \\
\hline 3D graphene & Haemoglobin & $92.7 \%$ & (Zhang et al., 2015) [86] \\
\hline 3D graphene & Haemoglobin & NA & (Chen et al., 2015) [87] \\
\hline Activated carbon & Ibuprofen and artemisinin & NA & $\begin{array}{c}\text { (Jolliffe and Gerogiorgis, } \\
\text { 2016) [88] }\end{array}$ \\
\hline Activated carbon & Bioactive tripeptide & $80 \%$ & (Rodriguez-Illera et al., \\
& & & 2015) [89] \\
\hline
\end{tabular}

*SWCNT: Single-walled carbon nanotubes, MWCNTs: Multi-walled carbon nanotubes; NA: not available

\section{Carbon nanotubes}

Carbon nanotubes (CNTs) have been investigated in separation approaches applied to the pharmaceutical and biomedical sectors, mainly due to their strong ability to interact with various bio(molecules) $[79,80]$. CNTs are cylindrical sheets formed by a hexagonal arrangement of $s p^{2}$ carbon-carbon bonds in nanoscale dimensions [90]. CNTs are classified as single-walled carbon nanotubes (SWNTs), having a diameter of 1-2 $\mathrm{nm}$, and as multi-walled carbon nanotubes (MWNTs), with an internal diameter of 5-50 nm [91]. MWNTs are composed of several concentric layers of graphite, whilst SWNTs only have one and form a tubular nanostructure [90]. Surface functionalization of CNTs is an effective method to design new materials of higher efficiency by coupling the properties of functional groups to the surface of CNTs [92]. The functionalization of CNTs is carried out by covalent and non-covalent methodologies, depending on the nature of the (bio)molecule to be linked [93]. Non-covalent functionalization (physical adsorption) has attracted a large interest because this method is easier to perform and retains the original properties of CNTs. Covalent functionalization (chemical bond formation) may produce defects in the wall structure of CNTs [93].

Drugs and biologics have been separated/purified using CNTs by solid phase extraction (SPE) [94-96]. The literature available indicates that CNTs present a high capacity for the adsorption of organic and inorganic molecules [97]. In many comparative studies, a similar or improved adsorption capacity was reported when comparing the performance of CNTs with silica-based sorbents [98]. The main interactions between CNTs and (bio)molecules include: ionic interactions, electrostatic forces, $\pi-\pi$ stacking, van der Waals forces and hydrogen-bonding [96]. The separation of chiral molecules is of great importance in the pharmaceuticals sector due to their different physiological and therapeutic effects [77], and CNTs 
have been used as a new technology for enantioseparation of chiral drugs [99]. In pharmaceutical industries, $56 \%$ of the drugs are chiral molecules and a large part comprises equimolar mixtures of two enantiomers [100]. Single-walled CNTs were used as chiral selectors for the separation of carvedilol stereoisomers (non-selective $\beta$-blocker with fluorescent detection) from a racemic mixture [77]. The separation of carvedilol stereoisomers was fast (less than $70 \mathrm{~s}$ ) being the composition of eluent solution $(\mathrm{HCl} / \mathrm{SDS}$ mixture, optimised ratio of 2) the main factor influencing the separation. In this work, carvedilol isomers were separated (97\% recovery) from a commercial pharmaceutical containing $12.5 \mathrm{mg}$ of the racemic mixture. More than 100 experiments were carried out with an adequate selectivity and high sensitivity, confirming the high stability of the single-walled CNTs employed [77]. In an additional work, MWCNTs were applied with high performance in the enantioseparation of racemic clenbuterol (a bronchodilator) [78]. A chiral stationary phase of MWCNT cross-linked with hydroxypropyl- $\beta$-cyclodextrin for the racemic clenbuterol separation was developed. The separation was qualitatively evaluated by thin-layer chromatography. The pristine MWCNTs was not effective as enantio-specific adsorbent. In contrast, the chiral selector modified MWCNTs with hydroxypropyl- $\beta$-cyclodextrin successfully allows the enantiomers separation [78].

SWCNTs and MWCNTs were evaluated as a solid-phase extraction adsorbent for cephalosporin antibiotics [79]. It was found that the antibiotics were strongly retained on the CNTs and recoveries above $80 \%$ were achieved by the addition of ammonium acetate into eluents [79]. For comparison, the antibiotics retention capacity of CNTs is highly superior to $\mathrm{C}_{18}$ and graphitized carbon blacks commonly used. This is due to strong interactions taking place between the graphitic ring structure of the CNTs and the compounds which contain a benzene ring [79].

Fluoroquinolones (one of the most important classes of antibiotics), namely norfloxacin, perfloxacin, ciprofloxacin and gatifloxacin, were isolated from spiked egg samples by molecularly imprinted polymers on the surface of magnetic CNTs [80]. The nanomaterial was modified using ofloxacin as a pseudo template, methacrylic acid as a functional monomer, and ethylene glycol dimethacrylate as a cross-linker. A rapid adsorption and high selectivity of the nanomaterial towards the fluoroquinolones were observed, with recoveries ranging between $95.2 \% \pm$ $3.2 \%$ to $100.7 \% \pm 3.1 \%$ [80]. In another work of the same research group, magnetic CNTs also modified with methacrylic acid as a functional monomer, and ethylene glycol dimethacrylate as a cross-linker, were applied as supports for the extraction of gatifloxacin (an antibiotic) from biological fluids, serum samples, coupled with HPLC [101]. A high adsorption capacity of $192.7 \mu \mathrm{g} \mathrm{mg}^{-1}$ and recoveries of $85.3 \pm$ $4.2 \%$ toward gatifloxacin were obtained [101]. 
As mentioned above, CNTs present a high capacity in the separation and purification of small drugs. Due to their strong interaction with other molecules, particularly with those containing benzene rings, CNTs have excellent adsorption capacity for biomolecules. Thus, CNTs have also been regarded as a powerful tool in the pharmaceutical industry for the separation and purification of biologics from different and complex biological media, such as biological fluids, plants or fermentative media.

Lysozyme (Lys), used as a therapeutic compound in gastrointestinal treatments and infections [102], was extracted with high efficiency using magnetic multiwall CNTs modified with dual hydroxyl functional ionic liquids (ILs) [81]. At the optimal experimental conditions, the amount of Lys adsorbed on the material reached $94.6 \mathrm{mg} \mathrm{g}^{-1}$, and the desorption ratio reached $91.6 \%$ with a recovery of nearly $97.8 \%$. For comparison, bovine serum albumin (BSA), trypsin (Try) and ovalbumin (OVA) were also extracted by the same method. These results showed that the extraction amount increased in the order: BSA $\left(31.4 \mathrm{mg} \mathrm{g}^{-1}\right)<$ OVA $(39.6$ $\left.\mathrm{mg} \mathrm{g}^{-1}\right)<\operatorname{Try}\left(73.3 \mathrm{mg} \mathrm{g}^{-1}\right)<$ Lys $\left(94.6 \mathrm{mg} \mathrm{g}^{-1}\right)$. Circular dichroism analysis indicated that the secondary structure of Lys was unchanged after its elution from the material [81]. The authors compared their results with published methods, and stated that the proposed method has unique characteristics, such as: i) the magnetic solid phase extraction saves time and efforts (the material can be easily collected and separated with an external magnetic field); ii) the magnetic multiwall CNTs have unique advantages, including a high surface area, high mechanical strength, and excellent chemical and thermal stabilities; and iii) the dual hydroxy functional ILs not only have the unique properties of ILs but also are able to establish stronger hydrogen bonds with the protein [81].

CNTs have also been used as a support for drugs and biological transport in vitro and in vivo [76]. For this purpose, many works have been carried out to discover functional CNTs with low toxicity able to transport target molecules [76]. However, medical implementations of CNTs as drug delivery systems are still impeded due to their toxicity [76].

\section{Graphene}

Graphene is a carbon-based material presenting a hexagonal structure composed of carbon atoms $[93,96]$. Graphene is described as the basis of all graphitic carbon materials since it is the building block for CNTs (effectively 'rolled up' graphene sheets), graphite (stacked graphene sheets held together by strong van der Waals forces) and fullerene (wrapped up into graphene ball with pentagonal and hexagonal faces) [103]. Graphene presents similar and unique physical and chemical properties when compared to CNTs, such as high electrical conductivity, 
high surface area, adsorption capacity and thermal stability [104]. Due to their improved compatibility and the possibility to control the surface characteristics, graphene and their derivatives are promising carbon materials for the separation, isolation and pre-concentration of drugs and biologics [105]. Due to the large delocalized $\pi$-electron system present in the graphene framework, strong interactions to molecules containing aromatic rings occur, making them a powerful material for protein adsorption $[93,98]$. In this way, various biomolecules have been isolated from complex matrices using graphene [93, 96]. In particular, graphene has played an important role in the separation and isolation of proteins from complex biological matrices [104].

Lys was extracted by a magnetic chitosan and graphene oxide-functional guanidinium IL composite [82]. The optimisation of the experimental conditions proved that the adsorption efficiency was affected by the concentration of protein, amount of IL, $\mathrm{pH}$ value, temperature and extraction time. The maximum amount of extracted Lys was $38.4 \mathrm{mg} \mathrm{g}^{-1}$, when hexabutylguanidinium chloride [diBOHTMG]Cl IL was added into the MCGO [82]. This material was easily regenerated and reused three times with no significant losses of protein adsorption efficiency [82]. In an additional work, Lys was selectively isolated from a complex matrix of chicken egg white using functionalized graphene composites, namely graphene oxide $(\mathrm{GO})$ modified with epichlorohydrin $(\mathrm{ECH})$, iminodiacetic acid (IDA) and 1-phenylboronic acid (1-PBA), and chelated with nickel ions (GOPBA-IDA-Ni composite) [83]. An adsorption efficiency of $96 \%\left(70.7 \mu \mathrm{g} \mathrm{mg}^{-1}\right)$ was observed for the protein, with $90 \%$ of recovery in the desorption step [83]. The authors concluded that the preparation of a functionalized graphene composite film facilitates rapid on-line isolation protocols, which is an alternative strategy for overcoming the difficulty in the manipulation of traditional GO nanosheets [83]. In an additional work, graphene oxide with 3-aminopropyldiethoxymethyl silane, as coupling agent, was used as a coating of a capillary column for the chromatographic separation of Lys and four proteins from egg white [84]. Lys with improved stability was efficiently separated from other proteins in a single run [84]. The successful separation of the proteins was due to electrostatic interactions suppression by the high-surface coverage of the GO on the capillary wall. $\pi-\pi$ interactions have also shown to play a significant role in the proteins separation [84].

The selective isolation of haemoglobin from human whole blood, a complex matrix, was achieved in the presence of graphene oxide nanosheets immobilized onto $\mathrm{SiO}_{2}$, allowing the adsorption of $85 \%\left(50.5 \mathrm{mg} \mathrm{g}^{-1}\right)$ of haemoglobin [85]. 80\% of haemoglobin was recovered after the desorption step. Circular dichroism analyses indicated that the $\mathrm{GO} / \mathrm{SiO}_{2}$ composites do not induce changes on the conformation of haemoglobin after the adsorption/desorption steps [85]. 
More recently, 3D graphene has attracted great interest in both industrial and academic areas due to their particular structures, namely graphene foams, aerogels, sponges and networks [106]. Compared to 2D graphene, the surface of 3D graphene structure has a high porosity, light weight, high surface area and fast mass/electron transport [107]. Due to its properties, 3D graphene has excellent performance and promising applications in the development of catalysts, absorbents, and sensors, and in biological and biomedical applications [104]. In addition, the biocompatibility of 3D graphene enables its use as a new-generation of materials for the purification of pharmaceuticals [108]. However, due to the short time span since its initial discovery, the purification of pharmaceuticals using such materials is still in its infancy, and most reports involving biologics have only appeared in the past few years. The selective extraction of haemoglobin from a complex biological sample matrix, human whole blood, was demonstrated using a 3D amylopectin-reduced graphene oxide framework, with an adsorption efficiency of $92.7 \%$ and a maximum adsorption capacity of $1010 \mathrm{mg} \mathrm{g}^{-1}$ [86]. In a similar work, $3 \mathrm{D}$ graphene/carbon nanotube aerogel was recently used for the isolation of haemoglobin [87]. The adsorption capacity of haemoglobin was increased to 3793 $\mathrm{mg} \mathrm{g}^{-1}$, suggesting the potential of 3D graphene for the extraction of proteins [87].

\section{Activated carbon}

Activated carbons (ACs) are highly versatile materials widely used as adsorbents for a large number of products [107, 108], representing a viable and economic alternative over resins [89]. Usually, ACs are applied to the adsorption/removal of organic contaminants [109]. However, their range of applications can be extended. For instance, in pharmaceuticals manufacturing, due to their adsorptive characteristics, ACs can be used as adsorbents for the removal of impurities from the final or intermediate product [109]. In fact, ACs were already used in the processing steps in the ibuprofen and artemisinin batch separation [88]. Another example includes the use of ACs for the purification of p-aminophenol, an intermediate in the production of pharmaceuticals [110]. On the other hand, since ACs have pores of small diameter $(<2 \mathrm{~nm})$, and complex geometry, the accessibility of large biomolecules to these pores can be limited, restricting their use for biologics manufacturing [111]. To overcome this limitation, ACs can be coated with a biocompatible membrane to change the adsorption capacities [111]. For instance, an antihypertensive lactotripeptide, a bioactive tripeptide, was extracted from a milk casein hydrolysate TensGuard ${ }^{\mathrm{TM}} \mathrm{S}$ using activated carbon packed bed as an alternative to resins [89]. It was obtained a yield of $80 \%$ in the third cycle, and a purity of $35 \%$. The adsorption yield of the bioactive tripeptide 
decreased with consecutive cycles; on the other hand, the desorption yield increased over the first 8 cycles [89].

\section{Magnetic particles and other (nano)materials}

Separation using magnetic particles offers several advantages over chromatographic techniques, such as the possibility of faster separation in a lower number of steps, reduction of protein degradation, low costs, scalability and chemical compatibility with ligands already used in derivatized silicas employed in chromatographic systems. The use of functionalized magnetic particles is now regarded as a true alternative for the separation of biologics from complex mixtures (Table 3) [112, 113]. This methodology has been applied in the separation of cells, proteins, peptides, nucleic acids, and pathogens [114]. Nevertheless, for many applications, magnetic separation remains as a laboratory-scale process, though the prospects are for its growing use [114].

Magnetic nanoparticles (MPs) for bioseparation usually contain an inorganic core having size dependent superparamagnetic/ferrimagnetic features. Iron oxides, such as magnetite $\left(\mathrm{Fe}_{3} \mathrm{O}_{4}\right)$ or maghemite $\left(\gamma-\mathrm{Fe}_{2} \mathrm{O}_{3}\right)$, are very often used with a protecting biocompatible coating: polymer, amorphous silica (Fig. 8) or noble metals that provide colloidal stability and solubility [114]. Depending on the application, further surface functionalization of these materials can be applied in order to promote interactions with target moieties [114]. 


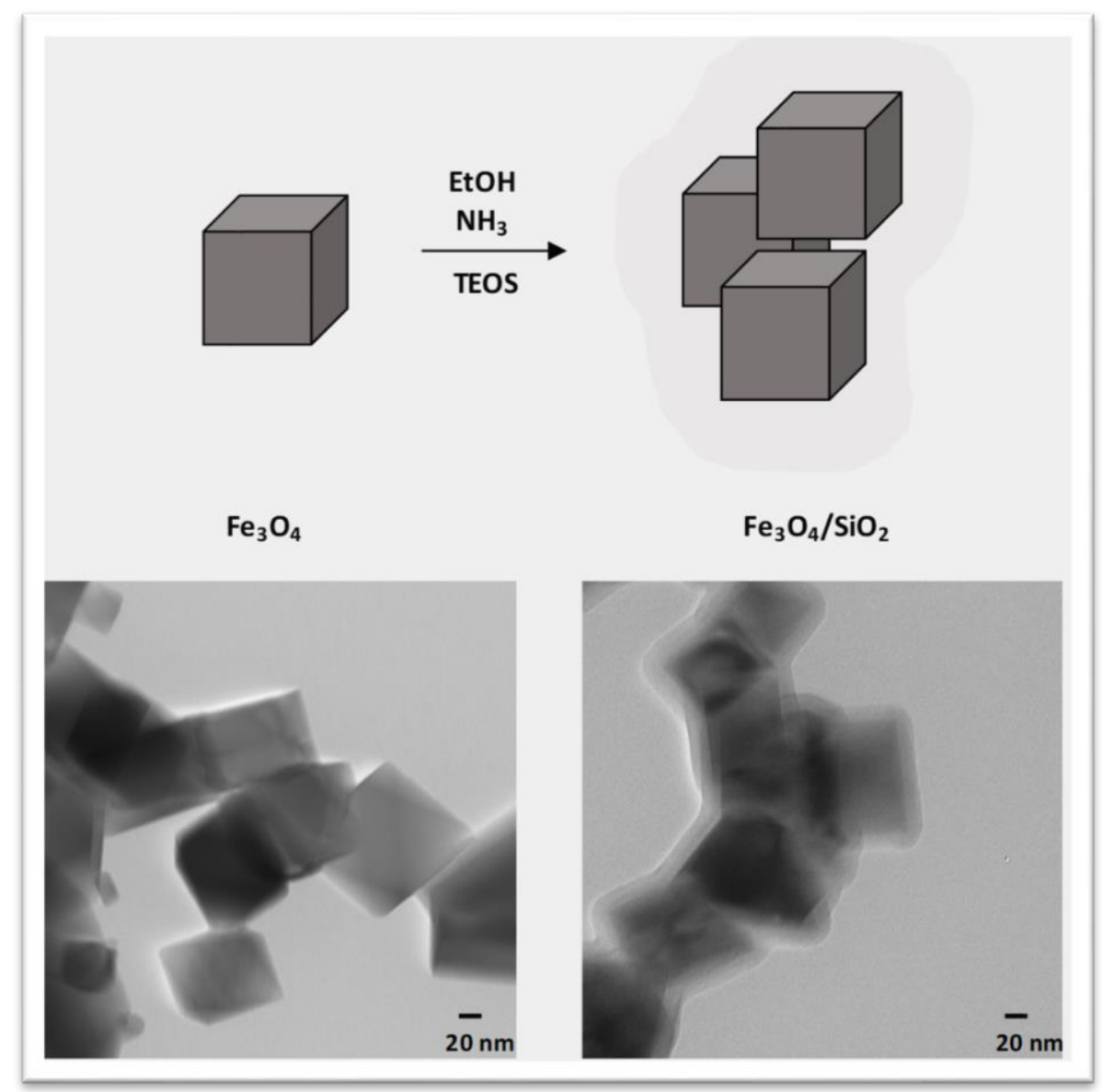

Figure 8: TEM images of magnetic nanoparticles (MPs) formed by a magnetic inorganic core of magnetite $\left(\mathrm{Fe}_{3} \mathrm{O}_{4}\right)$ with a protecting biocompatible layer of silica.

Magnetic silica adsorbents functionalized with silane coupling agents were applied in the separation of proteins $[115,116]$. Bovine serum albumin (BSA) and Lys proteins were adsorbed on MPs functionalized with amino groups (from the reaction with an amino-silane) at different $\mathrm{pH}$ values and in presence of carbodiimide in order to have direct binding with the protein [115]. The adsorption efficiency of BSA was up to $74 \%$ at a low $\mathrm{pH}$, but the value was reduced to $40 \%$ at higher $\mathrm{pH}$ values. The adsorption efficiency of Lys changed from $40 \%$ to $90 \%$, with an increase in the $\mathrm{pH}$. These results are justified by the $\mathrm{pI}$ values of the proteins, 4.6 and 11, for BSA and Lys, respectively. At these $\mathrm{pH}$ values, proteins present their original structure (most compact state) and there is a decrease in the electrostatic forces, thus allowing the interaction of the proteins with the amino groups on the MP surfaces [115]. 
Some purification methods employ a separation step based on specific interactions between his-tagged protein and $\mathrm{Ni}^{2+}$ sites. This affinity strategy can be combined with magnetic separation for better purification results, low eluent costs, and easiness in processing (avoiding centrifugation as the separation can be done with a magnetic field), and was already used in several purification processes $[113,117$ 119]. Functionalized magnetic silica adsorbents were used in the purification of the $\mathrm{N}$-terminal His-tagged recombinant small heat shock protein, Tpv-sHSP 14.3 [120]. In this study, after functionalization with amino-silane, -COOH groups were added to the surface of MPs, which then reacted with $\mathrm{N} \alpha, \mathrm{N} \alpha-\mathrm{Bis}$ (carboxymethyl)-Llysine hydrate (NTA) and finally were labelled with $\mathrm{Ni}^{2+}$ ions. This purification system has several advantages over other protein purification systems. There is no need for specialized binding buffers or substrates for protein elution, and all purification steps can be easily and quickly performed using a magnet for separation. A similar strategy was applied with $\mathrm{Ni}^{2+}$ tagged to $\mathrm{Fe}_{3} \mathrm{O}_{4} /$ hydroxyapatite MPs for the purification of His-tagged thioredoxin 9 [117] and with magnetite/gold nanoparticles functionalized with nickel(II)-nitrilotriacetate for the purification of His-tagged maltose binding protein directly from a cell extract [118].

Fernandes et al. [121] were pioneers in the use of functionalized MPs with Affitins for the separation of proteins [121]. Affitin H4 (anti-lysozyme) and Affitin D1Sso7d-DM (anti-IgG) were used to prepare affinity/magnetic adsorbents for the purification of lysozyme from Escherichia coli supernatants and IgG from human plasma, respectively. The authors stated that this methodology can be used for the purification of any protein given the versatility of Affitins. At the optimised conditions, yields of $58 \mathrm{mg}$ of lysozyme/g of support and $165 \mathrm{mg}$ of $\mathrm{IgG} / \mathrm{g}$ of support were obtained. In addition, the recovery of both proteins was above $95 \%$, with a purity of $95 \%$ and $81 \%$ for Lys and IgG, respectively [121].

Alves et al. [122] synthetized and tested MPs of iron oxide coated with gum arabic for the purification of antibodies. It was proved that using these low-cost adsorbents it was possible to purify IgG from the supernatant mammalian cell cultures, namely Chinese hamster ovary ( $\mathrm{CHO})$ and Hybridoma, by a cation exchange mechanism, achieving elution yields of $93.5 \%$. Given the simplicity and reduced costs of this purification strategy, the results obtained are very encouraging. In addition, the possibility of reusing MPs is an obvious economic advantage [122]. The same iron oxide, coated with gum arabic magnetic supports, were functionalized with two different triazine-based affinity ligands - ligand 22/8 (artificial Protein A) and ligand 8/7 (artificial Protein L) - with high specificity towards IgG [59]. Santana et al. [62] describe the purification of IgG from mammalian cell culture supernatants using dextran-coated MPs modified with ligand 22/8. In this case, and after elution at $\mathrm{pH} 11,95 \%$ of IgG was obtained. Chitosan-coated MPs functionalized with ConA were applied in the purification of IgG from human plasma with a loading of 70 
$\mathrm{mg} \mathrm{g}^{-1}$ and adsorption ratio of $63 \mathrm{mg} \mathrm{g}^{-1}$ [123]. The capture of IgG was also obtained with $200 \mathrm{~nm}$ MPs coated with protein A and starch [58]. In the latter, a hybrid system incorporating elements of both PEG precipitation and steric exclusion chromatography on $200 \mathrm{~nm}$ nanoparticles, coated with starch, allows the magnetic capture of $78 \mathrm{mg}$ of $\mathrm{IgG}$ per $\mathrm{mg}$ of particles. This corresponds to $58 \mathrm{~g}$ of $\mathrm{IgG}$ per $\mathrm{mg}$ of nanoparticles, which is roughly 1000 times higher than the average capacity of commercial packed bed columns based on protein-A porous particles. $69 \%$ of IgG recovery, purity values similar to protein-A and higher productivity than packed columns were achieved, suggesting that this strategy could evolve as a credible option for the industrial purification of monoclonal antibodies [58].

The purification of IgG from mammalian cell cultures was also studied with magnetic particles functionalized with boronic acid [63]. Comparing the performance of the functionalized MPs with boronic acid at $\mathrm{pH} 7.4$ and 8.5 with the same MPs functionalized with protein-A, it was verified that the former provided twice the binding capacity for IgG. However, there are some limitations derived from the presence of competing species with $\operatorname{IgG}$ in the mammalian cells culture (glycoproteins, carbohydrates and glycolipids from cell fragments), leading to the loss of binding capacity [63]. Beyond these disadvantages and considering the low cost and greater stability under alkaline conditions of boronic acid, this synthetic ligand may be an alternative to Protein A. In addition, unlike protein A, this ligand can be used in the purification of fragments of antibodies that do not have the Fc region.

$\mathrm{Fe}_{3} \mathrm{O}_{4}$ magnetic particles functionalized with gluteraldehyde were tested as adsorbents for three proteins: bovine haemoglobin $(\mathrm{BHb})$, bovine serum albumin (BSA) and lysozyme (Lyz) [124]. The adsorption capacities of MPs for the three proteins studied had an appreciable difference: $\mathrm{Lyz}>\mathrm{BHb}>\mathrm{BSA}$. This result may be justified by their different amino acids composition and $\mathrm{pI}$. The protein more easily adsorbed is the one with more alkaline amino acids and that establishes the stronger reversible imine bond with the adsorbent. A very relevant aspect is the reuse of these particles, which was achieved after treatment with a solution of oxalic acid and consequent breaking of imine bonds [124].

Immunoaffinity chromatography, which uses polyclonal, monoclonal or antiidiotypic antibodies as ligands, is a chromatographic technique which exhibits product recovery results far superior to other chromatographic techniques [125]. This strategy, coupled with magnetic separation, was used for the purification of transferrin (Tf) from artificial plasma. Transferrin (Tf) is a monomeric glycoprotein (80 $\mathrm{kDa}$ and $670-700$ amino acids in its composition). This glycoprotein is responsible for the maintenance of iron homeostasis through its uptake, storage and transport. This biopharmaceutical has been widely used in the treatment of diseases such as thalassemia, bacterial infections, diabetes and transferrinemia [125]. The 
adsorbent material was prepared by immobilizing the anti-transferrin antibody (Anti-Tf) in MPs of $\mathrm{Fe}_{3} \mathrm{O}_{4}$ coated with poly (glycidyl methacrylate) [125]. Although only artificial human plasma was used, anti-Tf magnetic particles adsorbed $0.1 \mathrm{mg} \mathrm{g}^{-1}$ of $\mathrm{Tf}$, with no albumin or IgG adsorption [125].

Table 3: Examples on the application of magnetic (nano)materials for the separation of (bio)pharmaceuticals.

\begin{tabular}{|c|c|c|c|}
\hline Magnetic material & Application & Adsorption capacity & Reference \\
\hline $\begin{array}{l}\text { MPs coated with gum arabic } \\
\text { magnetic functionalized with } \\
\text { two different triazine-based } \\
\text { affinity ligands }\end{array}$ & Purification of IgG & 344 mg IgG/gmaterial & $\begin{array}{l}\text { (Batalha et } \\
\text { al., 2010) } \\
{[59]}\end{array}$ \\
\hline $\begin{array}{l}\text { Dextran-coated MPs modified } \\
\text { with ligand } 22 / 8\end{array}$ & Purification of IgG & $95 \%$ IgG of purity & $\begin{array}{l}\text { (Santana et } \\
\text { al., 2012) } \\
{[62]}\end{array}$ \\
\hline $\begin{array}{l}\text { Magnetic silica functionalized } \\
\text { with amino-silane }\end{array}$ & $\begin{array}{l}\text { Adsorption of bovine } \\
\text { serum albumin and } \\
\text { lysozyme }\end{array}$ & $\begin{array}{l}\text { BSA: } 74 \% \\
\text { Lys: } 90 \%\end{array}$ & $\begin{array}{l}\text { (Chang et al., } \\
\text { 2008) [115] }\end{array}$ \\
\hline $\begin{array}{l}\text { Magnetite/gold nanoparticles } \\
\text { functionalized with nickel(II)- } \\
\text { nitrilotriacetate }\end{array}$ & His-tagged maltose & NA* & $\begin{array}{l}\text { (Quaresma et } \\
\text { al., 2014) } \\
{[118]}\end{array}$ \\
\hline $\begin{array}{l}\mathrm{Ni}^{2+} \text { tagged to } \\
\mathrm{Fe}_{3} \mathrm{O}_{4} / \text { hydroxyapatite } \\
\text { nanoparticles }\end{array}$ & His-tagged thioredoxin 9 & $12.98 \mathrm{mmol} / \mathrm{g}_{\text {material }}$ & $\begin{array}{l}\text { (Yao et al., } \\
\text { 2014) [119] }\end{array}$ \\
\hline $\begin{array}{l}\text { Magnetic silica functionalized } \\
\text { with } \mathrm{N} \alpha, \mathrm{N} \alpha- \\
\mathrm{Bis} \text { (carboxymethyl)-L-lysine } \\
\text { hydrate (NTA) and labelled with } \\
\mathrm{Ni}^{2+} \text { ions }\end{array}$ & $\begin{array}{l}\text { N-terminal His-tagged } \\
\text { recombinant protein } \\
\text { adsorption }\end{array}$ & $\mathrm{NA}^{*}$ & $\begin{array}{l}\text { (Aygar et al., } \\
2015)[120]\end{array}$ \\
\hline $\begin{array}{l}\text { Magnetic nanoparticles } \\
\text { functionalized with Affitins }\end{array}$ & $\begin{array}{l}\text { Purification of lysozyme } \\
\text { and } \operatorname{IgG}\end{array}$ & $\begin{array}{l}58 \mathrm{mg} \mathrm{lysozyme} / \mathrm{g}_{\text {material }} \\
65 \mathrm{mg} \mathrm{IgG} / \mathrm{g}_{\text {material }}\end{array}$ & $\begin{array}{l}\text { (Fernandes et } \\
\text { al., 2016) } \\
{[121]}\end{array}$ \\
\hline $\begin{array}{l}\text { MPs** of iron oxide coated } \\
\text { with gum arabic }\end{array}$ & Purification of IgG & $93.5 \%$ & $\begin{array}{l}\text { (Alves et al., } \\
2015)[122]\end{array}$ \\
\hline $\begin{array}{l}\text { Chitosan-coated MPs } \\
\text { functionalized with Con-A }\end{array}$ & Purification of IgG & $63 \mathrm{mg} / \mathrm{g}_{\text {material }}$ & $\begin{array}{l}\text { (Kavaz et al., } \\
\text { 2012) [123] }\end{array}$ \\
\hline $\begin{array}{l}\text { Magnetic particles } \\
\text { functionalized with } \\
\text { gluteraldehyde }\end{array}$ & $\begin{array}{l}\text { Adsorption of bovine } \\
\text { haemoglobin, bovine } \\
\text { serum albumin and } \\
\text { lysozyme }\end{array}$ & $\begin{array}{l}\text { Adsorption varied in } \\
\text { the range of } 10-50 \mathrm{mg}\end{array}$ & $\begin{array}{l}\text { (Gao et al., } \\
2015)[124]\end{array}$ \\
\hline $\begin{array}{l}\text { Magnetic particles of magnetite } \\
\text { coated with poly (glycidyl } \\
\text { methacrylate) }\end{array}$ & Purification of transferrin & $\begin{array}{l}\text { Adsorption of } 0.12 \\
\mathrm{mg} / \mathrm{g}_{\text {material }}\end{array}$ & $\begin{array}{l}\text { (Saçligil et } \\
\text { al., 2015) } \\
{[125]}\end{array}$ \\
\hline Surface active maghemite & Adsorption of corcumin & $>98 \%$ & $\begin{array}{l}\text { (Magro et } \\
\text { al., 2015) } \\
{[126]}\end{array}$ \\
\hline
\end{tabular}

In addition to silica-, carbon- and metal-oxide-based materials, other inorganic materials have been employed in biopharmaceuticals purification. Ralla et al. [127] 
developed a new stationary phase based on montmorillonite clays and amorphous silica for the purification of proteins, namely alkaline phosphatase (Ap), achymotrypsin (Chy), Hb, human serum albumin (HSA), Lys, ovalbumin (Ova) and trypsinogen (Try). The high porosity of the stationary phase makes the protein adsorption viable. The column packaging is only possible due to the presence of silica, which prevents the clay from swelling. Electrostatic interactions were found to be the main responsible for the absorption of proteins in the stationary phase (ruled by a cationic exchange mechanism). In addition to electrostatic interactions, hydrogen bonding and van der Waals forces are also involved in protein adsorption by the clay surfaces. Therefore, the adsorption selectivity for these proteins is lower than that displayed by commercial cation exchange stationary phases [127].

\section{GENERAL CONCLUSIONS AND FUTURE PROSPECTS}

In the next decades, demands for high quality medicines will continue to increase, while their intensive research and development is vital to the future of the pharmaceuticals sector. The industrial production of synthetic drugs (antibiotics, anti-inflammatory drugs, steroids, among others) and biologics (recombinant proteins, antibodies, and nucleic-acid-derived products) requires complex processes able to provide them with high quality and no side effects. The purification of pharmaceuticals included in the downstream processing is mainly carried out by chromatographic processes. Therefore, the development of more cost-effective production and purification technologies, either to improve the current chromatographic methods or to create new ones, is a top requirement in order to decrease the current costs of drugs, and in particular of biopharmaceuticals. The increasing number of scientific manuscripts found in this area demonstrates a remarkable interest in finding more effective medicines and to improve their production. Among these, a large interest has been placed in the development of alternative purification techniques, in which (nano)materials can be used. These efficient and fascinating multifunctional (nano)materials have a high loading capacity, stability, and can be designed to adsorb target pharmaceuticals through the incorporation of diverse functionalization groups.

This chapter overviewed the approaches used in the downstream processing of pharmaceuticals (including both synthetic drugs and biopharmaceuticals) using nanomaterials. Substantial progress has been made in downstream processes through the application of carbon nanomaterials (carbon nanotubes, graphene, and activated carbon), silica nanoparticles and magnetic nanoparticles. Among them, silica nanoparticles and CNTs are the most studied nanomaterials with promising results. From the topics here presented, nanoparticles may play a key role in the future of pharmaceuticals research and manufacturing. 
Both the global pharmaceutical market and regulatory agencies are forcing industries for enhanced quality and low cost. As presented in this book chapter, emerging technologies have allowed the ongoing trend of value-based care and have potential to motivate and transform the future of the (bio)pharmaceuticals industry to acquire competitive advantages, innovation, challenges and growth in manufacturing, while providing potential benefits to society.

\section{CONFLICT OF INTEREST}

The authors declare no conflict of interest, financial or otherwise.

\section{ACKNOWLEDGEMENTS}

This work was developed within the scope of the project CICECO-Aveiro Institute of Materials, POCI-01-0145-FEDER-007679 (FCT Ref. UID/CTM/50011/2013), financed by national funds through the FCT/MEC and when appropriate cofinanced by FEDER under the PT2020 Partnership Agreement. This work was also financially supported by the project POCI-01-0145-FEDER-031106 funded by FEDER, through COMPETE2020 - Programa Operacional Competitividade e Internacionalização (POCI), and by national funds (OE), through FCT/MCTES. M.C. Neves acknowledges FCT for the post-doctoral grant SFRH/BPD/110423/2015. A.P.M. Tavares acknowledges the FCT Investigator Programme (IF/01634/2015) with financing from the European Social Fund and the Human Potential Operational Programme. M.G. Freire acknowledges the European Research Council (ERC) for the Starting Grant ERC-2013-StG-337753.

\section{REFERENCES}

[1] Taylor D. The Pharmaceutical industry and the future of drug development. In: Hester RE, Harrison RM, Eds. Pharmaceuticals in the Environment. The Royal Society of Chemistry 2015. pp. 1-33.

[2] Würmseher M, Firmin L. Nanobiotech in big pharma: a business perspective. Nanomedicine 2017; 12(5): 535-43.

[3] Iheanacho I. Big Pharma: How the world's biggest drug companies control illness. Bmj 2006; 332(7542): 672.

[4] Kalyanpur M. Downstream Processing in the Biotechnology Industry. Mol Biotechnol 2002; 22(1): 087-98. 
[5] Buchholz S. Future manufacturing approaches in the chemical and pharmaceutical industry. Chem Eng Process Process Intensif 2010; 49(10): 993-5.

[6] Lybecker KM. Fraser Institute [homepage on the Internet]. The Biologics revolution in the production of drugs. [cited: July 12, 2016]. Available from: https://www.fraserinstitute.org/studies/biologicsrevolution-in-the-production-of-drugs

[7] Geigert J. The challenge of CMC regulatory compliance for biopharmaceuticals and other biologics. $2^{\text {nd }}$ edition. Springer. 2013; pp. $1-338$.

[8] Walsh G. Biopharmaceutical benchmarks 2014. Nat Biotechnol 2014; 32(10): 992-1000.

[9] Tsang L, Cortez N. Biopharmaceuticals: Definition and Regulation. In: Pharmaceutical Sciences Encyclopedia: Drug Discovery, Development, and Manufacturing John Wiley \& Sons, Inc.; 2010. pp. $1-18$.

[10] Guiochon G, Beaver LA. Separation science is the key to successful biopharmaceuticals. J Chromatogr A 2011; 1218(49): 8836-58.

[11] The MJ. Human insulin: DNA technology's first drug. Am J Hosp Pharm 1989; 46: 9-11.

[12] Kretzmer G. Industrial processes with animal cells. Appl Microbiol Biotechnol 2002; 59(2-3): 135-42.

[13] Sanchez-Garcia L, Martín L, Mangues R, Ferrer-Miralles N, Vázquez E, Villaverde A. Recombinant pharmaceuticals from microbial cells: A 2015 update. Microb Cell Fact 2016; 15(1): 1-7.

[14] Rosa PAJ, Ferreira IF, Azevedo AM, Aires-Barros MR. Aqueous twophase systems: A viable platform in the manufacturing of biopharmaceuticals. J Chromatogr A 2010; 1217(16): 2296-305.

[15] Morrow T, Felcone LH. Defining the difference: What makes biologics unique. Biotechnol Healthc 2004; 1(4): 24-9.

[16] Ledón N, Lage A. Biosimilars and the real world. MEDICC Rev 2017; 19(4): 9-14.

[17] Rader RA. (Re)defining biopharmaceutical. Nat Biotechnol 2008; 26(7): 743-51.

[18] Genazzani AA, Biggio G, Caputi AP, Del Tacca M, Drago F, Fantozzi R, et al. Biosimilar Drugs. BioDrugs 2007; 21(6): 351-6.

[19] Azevedo V, Hassett B, Fonseca JE, Atsumi T, Coindreau J, Jacobs I, et al. Differentiating biosimilarity and comparability in biotherapeutics. Clin Rheumatol 2016; 35(12): 2877-86. 
[20] Morais JAG, Lobato MDR. The new european medicines agency guideline on the investigation of bioequivalence. Basic Clin Pharmacol Toxicol 2010; 106(3): 221-5.

[21] Beck A, Reichert JM. Approval of the first biosimilar antibodies in Europe: A major landmark for the biopharmaceutical industry. MAbs 2013; 5(5): 621-3.

[22] Khraishi M, Stead D, Lukas M, Scotte F, Schmid H. Biosimilars: A multidisciplinary perspective. Clin Ther 2016; 38(5): 1238-49.

[23] Stevenson JG, Popovian R, Jacobs I, Hurst S, Shane LG. Biosimilars: practical considerations for pharmacists. Ann Pharmacother 2017; 51(7): 590-602.

[24] Jacobs I, Petersel D, Isakov L, Lula S, Lea Sewell K. Biosimilars for the Treatment of Chronic Inflammatory Diseases: A Systematic Review of Published Evidence. BioDrugs 2016; 30(6): 525-70.

[25] Ramanan S, Grampp G. Drift, evolution, and divergence in biologics and biosimilars manufacturing. BioDrugs 2014; 28(4): 363-72.

[26] Ebbers HC, Chamberlain P. Controversies in establishing biosimilarity: extrapolation of indications and global labeling practices. BioDrugs 2016; 30(1): 1-8.

[27] Mellstedt H, Niederwieser D, Ludwig H. The challenge of biosimilars. Ann Oncol 2008; 19(3): 411-9.

[28] Fisher AC, Lee SL, Harris DP, Buhse L, Kozlowski S, Yu L, et al. Advancing pharmaceutical quality: An overview of science and research in the U.S. FDA's Office of Pharmaceutical Quality. Int J Pharm 2016; 515(1-2): 390-402.

[29] Swain MP, Patra M, Patnaik M. Excipients and Its Variation in Pharmaceutical Aerosol Formulation: a review. Innov Int J Med Pharm Sci 2016; 1(1): 4-8.

[30] Eastgate MD, Schmidt MA, Fandrick KR. On the design of complex drug candidate syntheses in the pharmaceutical industry. Nat Rev Chem 2017; 1: 1-16.

[31] Larsson DGJ. Pollution from drug manufacturing: review and perspectives. Philos Trans R Soc Lond B Biol Sci 2014; 369(1656): 20130571-.

[32] O'Connor TF, Yu LX, Lee SL. Emerging technology: A key enabler for modernizing pharmaceutical manufacturing and advancing product quality. Int J Pharm 2016; 509(1-2): 492-8.

[33] FDA. Pharmaceutical CGMPs for the 21s Century - A risk-based approach. Food and Drug Administration. 2004. 
[34] Teżyk M, Milanowski B, Ernst A, Lulek J. Recent progress in continuous and semi-continuous processing of solid oral dosage forms: A review. Drug Dev Ind Pharm 2015; 42(8): 1195-214.

[35] Lee SL, O'Connor TF, Yang X, Cruz CN, Chatterjee S, Madurawe RD, et al. Modernizing pharmaceutical manufacturing: from batch to continuous production. J Pharm Innov 2015; 10(3): 191-9.

[36] Allison G, Cain YT, Cooney C, Garcia T, Bizjak TG, Holte O, et al. Regulatory and quality considerations for continuous manufacturing May 20-21, 2014 continuous manufacturing symposium. J Pharm Sci 2015; 104(3): 803-12.

[37] Langhauser K. Pharmaceutical manufacturing [homepage on the Internet]. Janssen's Historic FDA Approval. [cited: April 13, 2016]. Available from: https://www.pharmamanufacturing.com/articles/2016/janssenshistoric-fda-approval/

[38] Norman J, Madurawe RD, Moore CMV, Khan MA, Khairuzzaman A. A new chapter in pharmaceutical manufacturing: 3D-printed drug products. Adv Drug Deliv Rev 2017; 108: 39-50.

[39] Kolakovic R, Viitala T, Ihalainen P, Genina N, Peltonen J, Sandler N. Printing technologies in fabrication of drug delivery systems. Expert Opin Drug Deliv 2013; 10(12): 1711-23.

[40] Goyanes A, Chang H, Sedough D, Hatton GB, Wang J, Buanz A, et al. Fabrication of controlled-release budesonide tablets via desktop (FDM) 3D printing. Int J Pharm 2015; 496(2): 414-20.

[41] Pardeike J, Strohmeier DM, Schrödl N, Voura C, Gruber M, Khinast $\mathrm{JG}$, et al. Nanosuspensions as advanced printing ink for accurate dosing of poorly soluble drugs in personalized medicines. Int J Pharm 2011; 420(1): 93-100.

[42] Vulto AG, Jaquez OA. The process defines the product: what really matters in biosimilar design and production? Rheumatology (Oxford) 2017; 56(4): 14-29.

[43] Kantardjieff A, Zhou W. Mammalian Cell cultures for biologics manufacturing. Adv Biochem Eng Biotechnol 2014; 129(July 2015): $1-9$.

[44] Spadiut O, Capone S, Krainer F, Glieder A, Herwig C. Microbials for the production of monoclonal antibodies and antibody fragments. Trends Biotechnol 2014; 32(1): 54-60.

[45] Berkowitz S, Engen J, Mazzeo J, Jones G. Analytical tools for characterizing biopharmaceuticals and the implications for biosimilars. Nat Rev Drug Discov 2013; 11(7): 527-40. 
[46] Conner J, Wuchterl D, Lopez M, Minshall B, Prusti R, Boclair D, et al. The Biomanufacturing of Biotechnology Products. Biotechnology Entrepreneurship: Starting, Managing, and Leading Biotech Companies. Elsevier; 2014; pp. 351-385.

[47] Higsmith J. BCC Research [homepage on the Internet]. Separation Systems for Commercial Biotechnology - Code: BIO011F. [cited: August 2013]. Available from: https://www.bccresearch.com/marketresearch/biotechnology/separation-systems-commercialbiotechnology-bio011f.html

[48] Hanke AT, Ottens M. Purifying biopharmaceuticals: knowledge-based chromatographic process development. Trends Biotechnol 2014; 32(4): 210-20.

[49] Bao Y, Shi C, Wang T, Li X, Ma J. Recent progress in hollow silica: Template synthesis, morphologies and applications. Microporous Mesoporous Mater 2016; 227: 121-36.

[50] Sun B, Zhou G, Zhang H. Synthesis, functionalization, and applications of morphology-controllable silica-based nanostructures: A review. Prog Solid State Chem 2016; 44(1): 1-19.

[51] Ciriminna R, Fidalgo A, Pandarus V, Béland F, Ilharco LM, Pagliaro $M$. The sol-gel route to advanced silica-based materials and recent applications. Chem Rev 2013; 113(8): 6592-620.

[52] Ren-Qi W, Teng-Teng O, Siu-Choon N, Weihua T. Recent advances in pharmaceutical separations with supercritical fluid chromatography using chiral stationary phases. TrAC - Trends Anal Chem 2012; 37: 83100.

[53] Barroso T, Lourenço A, Araújo M, Bonifácio VDB, Roque ACA, Aguiar-Ricardo A. A green approach toward antibody purification: A sustainable biomimetic ligand for direct immobilization on (bio)polymeric supports. J Mol Rec 2013; 26: 662-71.

[54] Rosa PAJ, Azevedo AM, Sommerfeld S, Bäcker W, Aires-Barros MR. Aqueous two-phase extraction as a platform in the biomanufacturing industry: Economical and environmental sustainability. Biotechnol Adv 2011; 29(6): 559-67.

[55] Qian H, Li C, Zhang Y, Lin Z. Efficient isolation of immunoglobulin $\mathrm{G}$ by paramagnetic polymer beads modified with 2-mercapto-4-mythylpyrimidine. J Immunol Met 2009; 343: 119-29.

[56] Lee S, Ahn C, Lee J, Lee J, Chang J. Rapid and selective separation for mixed proteins with thiol functionalized magnetic nanoparticles. Nanoscale Res Lett 2012; 7: 279. 
[57] Qian H, Li C, Lin Z, Zhang Y. Using thiophilic magnetic beads in purification of antibodies from human serum. Colloids Surf B Biointerfaces 2010; 75: 342-8.

[58] Gagnon P, Toh P, Lee J. High productivity purification of immunoglobulin $\mathrm{G}$ monoclonal antibodies on starch-coated magnetic nanoparticles by steric exclusion of polyethylene glycol. J Chromatogr A 2014; 1324: 171-80.

[59] Batalha IL, Hussain A, Roque ACA. Gum arabic coated magnetic nanoparticles with affinity ligands specific for antibodies. J Mol Recognit 2010; 23(5): 462-71.

[60] Barroso T, Temtem M, Hussain A, Aguiar-Ricardo A, Roque ACA. Preparation and characterization of a cellulose affinity membrane for human immunoglobulin G (IgG) purification. J Membr Sci. 2010; 348: 224-30.

[61] Ma Z, Ramakrishna S. Electrospun regenerated cellulose nanofiber affinity membrane functionalized with protein $A / G$ for $\operatorname{IgG}$ purification. J Membr Sci 2008; 319: 23-8.

[62] Santana SDF, Dhadge VL, Roque ACA. Dextran-coated magnetic supports modified with a biomimetic ligand for IgG purification. Appl Mat Int 2012; 4: 5907-14.

[63] Borlido L, Azevedo AM, Roque ACA, Aires-Barros MR. Potential of boronic acid functionalized magnetic particles in the adsorption of human antibodies under mammalian cell culture conditions. J Chromatogr A 2011; 1218(43): 7821-7.

[64] Hikosaka R, Nagata F, Tomita M, Kato K. Optimization of pore structure and particle morphology of mesoporous silica for antibody adsorption for use in affinity chromatography. Appl Surf Sci 2016; 384: 27-35.

[65] Li B, Zou X, Zhao Y, Sun L, Li S. Biofunctionalization of silica microspheres for protein separation. Mater Sci Eng C 2013; 33(5): 2595-600.

[66] Nakanishi K, Tomita M, Nakamura H, Kato K. Specific binding of immunoglobulin $\mathrm{G}$ to protein A-mesoporous silica composites for affinity column chromatography. J Mater Chem B 2013; 1: 6321-8.

[67] Saylan Y, Üzek R, Uzun L, Denizli A. Surface imprinting approach for preparing specific adsorbent for IgG separation. J Biomater Sci Polym Ed 2014; 25(9): 881-94.

[68] Liu Y, Feng J, Xiao Y, Guo Z, Zhang J, Xue X, et al. Purification of active bufadienolides from toad skin by preparative reversed-phase 
liquid chromatography coupled with hydrophilic interaction chromatography. J Sep Sci 2010; 33(10): 1487-94.

[69] Yin Y, Wei G, Zou X, Zhao Y. Functionalized hollow silica nanospheres for His-tagged protein purification. Sensors Actuators, B Chem 2015; 209: 701-5.

[70] Soares B, Passos H, Freire C, Coutinho JAP, Silvestre AJD, Freire MG. Ionic liquids in chromatographic and electrophoretic techniques: toward additional improvements on the separation of natural compounds. Green Chem 2016; 18: 4582-604.

[71] Van Doorslaer C, Wahlen J, Mertens P, Binnemans K, De Vos D. Immobilization of molecular catalysts in supported ionic liquid phases. Dalton Trans 2010; 39: 8377-90.

[72] Lemus J, Palomar J, Gilarranz M a., Rodriguez JJ. Characterization of Supported Ionic Liquid Phase (SILP) materials prepared from different supports. Adsorption 2011; 17: 561-71.

[73] Bi W, Zhou J, Row KH. Solid phase extraction of lactic acid from fermentation broth by anion-exchangeable silica confined ionic liquids. Talanta 2011; 83(3): 974-9.

[74] Wen J, Xu Y, Li H, Lu A, Sun S. Recent applications of carbon nanomaterials in fluorescence biosensing and bioimaging. Chem Commun 2015; 51(57): 11346-58.

[75] Freitas RA. What is nanomedicine? Nanomedicine Nanotechnology, Biol Med 2005; 1(1): 2-9.

[76] Chakrabarti M, Kiseleva R, Vertegel A, Ray SK. Carbon Nanomaterials for Drug Delivery and Cancer Therapy. J Nanosci Nanotechnol 2015; 15(8): 5501-11.

[77] Silva RA, Talío MC, Luconi MO, Fernández LP. Evaluation of carbon nanotubes as chiral selectors for continuous-flow enantiomeric separation of carvedilol with fluorescent detection. J Pharm Biomed Anal 2012; 70: 631-5.

[78] Yu J, Huang D, Huang K, Hong Y. Preparation of Hydroxypropyl- $\beta$ cyclodextrin Cross-linked Multi-walled Carbon Nanotubes and Their Application in Enantioseparation of Clenbuterol. Chinese J Chem 2011; 29: 893-7.

[79] Niu H, Cai Y, Shi Y, Wei F, Liu J, Mou S, et al. Evaluation of carbon nanotubes as a solid-phase extraction adsorbent for the extraction of cephalosporins antibiotics, sulfonamides and phenolic compounds from aqueous solution. Anal Chim Acta 2007; 594(1): 81-92.

[80] Xiao D, Dramou P, Xiong N, He H, Yuan D, Dai H. Preparation of molecularly imprinted polymers on the surface of magnetic carbon 
nanotubes with a pseudo template for rapid simultaneous extraction of four fluoroquinolones in egg samples. Analyst 2013; 138: 3287-96.

[81] Chen J, Wang Y, Huang Y, Xu K, Li N, Wen Q, et al. Magnetic multiwall carbon nanotubes modified with dual hydroxy functional ionic liquid for the solid-phase extraction of protein. Analyst 2015; 140(10): 3474-83.

[82] Ding X, Wang Y, Wang Y, Pan Q, Chen J, Huang Y, et al. Preparation of magnetic chitosan and graphene oxide-functional guanidinium ionic liquid composite for the solid-phase extraction of protein. Anal Chim Acta 2015; 861: 36-46.

[83] Liu J-W, Yang T, Chen S, Chen X-W, Wang J-H. Nickel chelating functionalization of graphene composite for metal affinity membrane isolation of lysozyme. J Mater Chem B 2013; 1(6): 810-8.

[84] Qu Q, Gu C, Hu X. Capillary coated with graphene and graphene oxide sheets as stationary phase for capillary electrochromatography and capillary liquid chromatography. Anal Chem 2012; 84(20): 8880-90.

[85] Liu JW, Zhang Q, Chen XW, Wang JH. Surface assembly of graphene oxide nanosheets on $\mathrm{SiO} 2$ particles for the selective isolation of hemoglobin. Chem - A Eur J 2011; 17(17): 4864-70.

[86] Zhang Y, Liu J-W, Chen X-W, Wang J-H. A three-dimensional amylopectin-reduced graphene oxide framework for efficient adsorption and removal of hemoglobin. J Mater Chem B 2015; 3(6): 983-9.

[87] Chen X, Zheng X, Wang X, Wang J. Graphene/Carbon Nanotube Aerogel with Ultra-high Adsorption Capacity for the Isolation of Hemoglobin. Chem J Chinese Univ 2015; 36(8): 1498-504.

[88] Jolliffe HG, Gerogiorgis DI. Plantwide design and economic evaluation of two Continuous Pharmaceutical Manufacturing (CPM) cases: Ibuprofen and artemisinin. Comput Chem Eng 2016; 91: 269-88.

[89] Rodriguez-Illera M, Ramires Ferreira Da Silva A, Boom RM, Janssen AEM. Recovery of a bioactive tripeptide from a crude hydrolysate using activated carbon. Food Bioprod Process 2015; 94(March): 25562.

[90] Feng W, Ji P. Enzymes immobilized on carbon nanotubes. Biotechnol Adv 2011; 29(6): 889-95.

[91] Liang X, Liu S, Wang S, Guo Y, Jiang S. Carbon-based sorbents: Carbon nanotubes. J Chromatogr A 2014; 1357: 53-67.

[92] Vardharajula S, Ali SZ, Tiwari PM, Eroğlu E, Vig K, Dennis VA, et al. Functionalized carbon nanotubes: Biomedical applications. Int $\mathrm{J}$ Nanomedicine 2012; 7: 5361-74. 
[93] Mital V. Carbon Nanotubes Surface Modifi cations: An Overview. Surf Modif cation Nanotub Fill 2011; 1-24.

[94] Serpell CJ, Kostarelos K, Davis BG. Can carbon nanotubes deliver on their promise in biology? Harnessing unique properties for unparalleled applications. ACS Cent Sci 2016; 2(4): 190-200.

[95] Sajid MI, Jamshaid U, Jamshaid T, Zafar N, Fessi H, Elaissari A. Carbon nanotubes from synthesis to in vivo biomedical applications. Int J Pharm 2016; 501(1-2): 278-99.

[96] Ravelo-Pérez LM, Herrera-Herrera A V., Hernández-Borges J, Rodríguez-Delgado MÁ. Carbon nanotubes: Solid-phase extraction. J Chromatogr A 2010; 1217(16): 2618-41.

[97] Ong YT, Ahmad AL, Hussein S, Zein S, Tan SH. A review on carbon nanotubes in an environmental protection and green engineering perspective. Brazilian J Chem Engi 2010; 27(02): 227-42.

[98] El-Sheikh AH, Sweileh JA, Al-Degs YS, Insisi AA, Al-Rabady N. Critical evaluation and comparison of enrichment efficiency of multiwalled carbon nanotubes, C18 silica and activated carbon towards some pesticides from environmental waters. Talanta 2008; 74(5): 1675-80.

[99] He H, Pham-Huy LA, Dramou P, Xiao D, Zuo P, Pham-Huy C. Carbon nanotubes: Applications in pharmacy and medicine. Biomed Res Int 2013; 2013.

[100] Nguyen LA, He H, Pham-Huy C. Chiral drugs: an overview. Int J Biomed Sci 2006; 2(2): 85-100.

[101] Xiao D, Dramou P, Xiong N, He H, Li H, Yuan D, et al. Development of novel molecularly imprinted magnetic solid-phase extraction materials based on magnetic carbon nanotubes and their application for the determination of gatifloxacin in serum samples coupled with high performance liquid chromatography. J Chromatogr A 2013; 1274: 4453.

[102] Sava G. Pharmacological aspects and therapeutic applications of lysozymes. EXS 1996; 75: 433-49.

[103] Geim AK, Novoselov KS. The rise of graphene. Nat Mater 2007; 6: 183-91.

[104] Chen X, Hai X, Wang J. Graphene/graphene oxide and their derivatives in the separation/isolation and preconcentration of protein species: A review. Anal Chim Acta 2016; 922: 1-10.

[105] Randviir EP, Brownson DAC, Banks CE. A decade of graphene research: Production, applications and outlook. Mater Today 2014; 17(9): 426-32. 
[106] Xia XH, Chao DL, Zhang YQ, Shen ZX, Fan HJ. Three-dimensional graphene and their integrated electrodes. Nano Today 2014; 9(6): 785807.

[107] Ma Y, Chen Y. Three-dimensional graphene networks: synthesis, properties and applications. NSR 2015; 2(1): 40-53.

[108] Tyagi MG, Albert AP, Tyagi V, Hema R. Graphene nanomaterial and applications in Biomedical Scinces. World J Pharm Pharm Sci 2013; 3(1): 339-45.

[109] Chandrawanshi H, Pilaniya U, Manchandani P, Jain P, Singh N, Pilaniya K. Recent trends in the impurity profile of pharmaceuticals. J Adv Pharm Technol Res 2010; 1(3): 302.

[110] Baron FA, Benner RG, Weinberg A. United States Patent 3694508. 1972.

[111] Kharlamova M V., Mochalin VN, Lukatskaya MR, Niu J, Presser V, Mikhalovsky S, et al. Adsorption of proteins in channels of carbon nanotubes: Effect of surface chemistry. Mater Express 2013; 3(1): 110 .

[112] Trindade T, Daniel AL. Nanocomposite Particles for Bio-Applications: Materials and Bio-applications. Trindade T, Daniel AL, editors. Pan Stranford; 2012. pp. 3-5.

[113] Fields C, Li P, O’Mahony JJ, Lee GU. Advances in affinity ligandfunctionalized nanomaterials for biomagnetic separation. Biotechnol Bioeng. 2016; 113: 11-25.

[114] Yildiz I. Applications of magnetic nanoparticles in biomedical separation and purification. Nanotechnol Rev 2016; 5(3): 331.

[115] Chang JH, Kang KH, Choi J, Jeong YK. High efficiency protein separation with organosilane assembled silica coated magnetic nanoparticles. Superlattices Microstruct 2008; 44(4-5): 442-8.

[116] Ferreira JA, Daniel-Da-Silva AL, Alves RMP, Duarte D, Vieira I, Santos LL, et al. Synthesis and optimization of lectin functionalized nanoprobes for the selective recovery of glycoproteins from human body fluids. Anal Chem 2011; 83(18): 7035-43.

[117] Yao S, Yan X, Zhao Y, Li B, Sun L. Selective binding and magnetic separation of histidine-tagged proteins using $\mathrm{Ni}^{2+}$-decorated $\mathrm{Fe}_{3} \mathrm{O}_{4} /$ hydroxyapatite composite nanoparticles. Mater Lett 2014; 126 : 97-100.

[118] Quaresma P, Osório I, Dória G, Carvalho PA, Pereira A, Langer J, et al. Star-shaped magnetite@gold nanoparticles for protein magnetic separation and SERS detection. RSC Adv 2014; 4(8): 3690-8. 
[119] Masthoff IC, David F, Wittmann C, Garnweitner G. Functionalization of magnetic nanoparticles with high-binding capacity for affinity separation of therapeutic proteins. J Nanoparticle Res 2014; 16.

[120] Aygar G, Kaya M, Özkan N, Kocabiyık S, Volkan M. Preparation of silica coated cobalt ferrite magnetic nanoparticles for the purification of histidine-tagged proteins. J Phys Chem Solids 2015; 87: 64-71.

[121] Fernandes CSM, dos Santos R, Ottengy S, Viecinski AC, Behar G, Mouratou B, et al. Affitins for protein purification by affinity magnetic fishing. J Chromatogr A 2016; 1457: 50-8.

[122] Alves BM, Borlido L, Rosa SASL, Silva MFF, Aires-Barros MR, Roque ACA, et al. Purification of human antibodies from animal cell cultures using gum arabic coated magnetic particles. J Chem Technol Biotechnol 2015; 90: 838-46.

[123] Kavaz D, Odabaş S, Denkbaş EB, Vaseashta A. A practical methodology for IgG purification via chitosan based magnetic nanoparticles. Dig J Nanomater Biostructures 2012; 7(3): 1165-77.

[124] Gao R, Hao Y, Cui X, Zhang L, Liu D, Tang Y. One-step synthesis of aldehyde-functionalized magnetic nanoparticles as adsorbent for fast and effective adsorption of proteins. J Alloys Compd 2015; 637: 4615.

[125] Saçligil D, Şenel S, Yavuz H, Denizli A. Purification of transferrin by magnetic immunoaffinity beads. J Sep Sci 2015; 38(15): 2729-36.

[126] Magro M, Campos R, Baratella D, Ferreira MI, Bonaiuto E, Corraducci $\mathrm{V}$, et al. Magnetic purification of curcumin from Curcuma longa rhizome by novel naked maghemite nanoparticles. J Agric Food Chem 2015; 63(3): 912-20.

[127] Ralla K, Sohling U, Riechers D, Kasper C, Ruf F, Scheper T. Adsorption and separation of proteins by a smectitic clay mineral. Bioprocess Biosyst Eng 2010; 33(7): 847-61. 